DEVELOPMENT AND TECHNOLOGY TRANSFER OF THE BNL FLAME QUALITY INDICATOR FOR OIL-FIRED APPLICATIONS

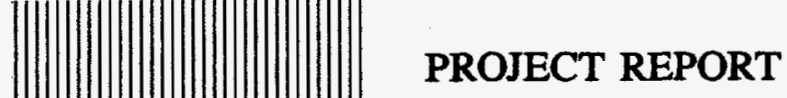

Thomas A. Butcher, Wai Lin Litzke, and Roger J. McDonald

September 1994

Prepared for:

Office of Building Technologies

U.S. Department of Energy

Washington, DC 20585

Energy Efficiency and Conservation Division DEPARTMENT OF APPLIED SCIENCE

BROOKHAVEN NATIONAL LABORATORY UPTON, LONG ISLAND, NEW YORK 11973 


\title{
DEVELOPMENT AND TECHNOLOGY TRANSFER OF THE BNL FLAME QUALITY INDICATOR FOR OIL-FIRED APPLIANCES
}

\author{
PROJECT REPORT
}

Thomas A. Butcher, Wai Lin Litzke, and Roger J. McDonald

September 1994

\author{
Prepared for the \\ BUILDING EQUIPMENT DIVISION \\ OFFICE OF BUILDING TECHNOLOGIES \\ UNITED STATES DEPARTMENT OF ENERGY
}

DEPARTMENT OF APPLIED SCIENCE

BROOKHAVEN NATIONAL LABORATORY

ASSOCIATED UNIVERSITIES, INC.

Under Contract No. DE-AC02-76CH00016 with the

UNITED STATES DEPARTMENT OF ENERGY

DISTRIBUTION OF THIS DOCUMENT IS UNLMITED 


\section{DISCLAIMER}

This report was prepared as an account of work sponsored by an agency of the United States Government. Neither the United States Government nor any agency thereof, nor any of their employees, nor any of their contractors, subcontractors, or their employees makes any warranty, express or implied, or assumes any legal liability or responsibility for the accuracy, completeness, or usefulness of any information, apparatus, product or process disclosed, or represents that its use would not infringe privately owned rights. Reference herein to any specific commercial product, process, or service by trade name, trademark, manufacturer, or otherwise, does not necessarily constitute or imply its endorsement, recommendation, or favoring by the United States Government or any agency thereof. The views and opinions of authors expressed herein do not necessarily state or reflect those of the United States Government or any agency, contractor, or subcontractor thereof. 


\section{DISCLAIMER}

Portions of this document may be illegible in electronic image products. Images are produced from the best available original document. 


\section{ABSTRACT}

The purpose of a flame quality indicator is to continuously and closely monitor the quality of the flame to determine a heating system's operating performance. The most efficient operation of a system is achieved under clean burning conditions at low excess air level. By adjusting a burner to function in such a manner, monitoring the unit to maintain these conditions can be accomplished with a simple, cheap and reliable device.

This report details the development of the Flame Quality Indicator (FQI) at Brookhaven National Laboratory for residential oil-heating equipment. It includes information on the initial testing of the original design, field testing with other cooperating organizations, changes and improvements to the design, and finally technology transfer and commercialization activities geared towards the development of commercially available products designed for the oil heat marketplace. As a result of this work, a patent for the technology was obtained by the U.S. Department of Energy (DOE). Efforts to commercialize the technology have resulted in a high level of interest amongst industry members including boiler manufacturers, controls manufacturers, oil dealers, and service organizations. To date DOE has issued licenses to three different manufacturers, on a non-exclusive basis, to design, build, and sell FQIs.

\section{DISCLAIMER}

This report was prepared as an account of work sponsored by an agency of the United States Government. Neither the United States Government nor any agency thereof, nor any of their employees, makes any warranty, express or implied, or assumes any legal liability or responsibility for the accuracy, completeness, or usefulness of any information, apparatus, product, or process disclosed, or represents that its use would not infringe privately owned rights. Reference herein to any specific commercial product, process, or service by trade name, trademark, manufacturer, or otherwise does not necessarily constitute or imply its endorsement, recommendation, or favoring by the United States Government or any agency thereof. The views and opinions of authors expressed herein do not necessarily state or reflect those of the United States Government or any agency thereof. 



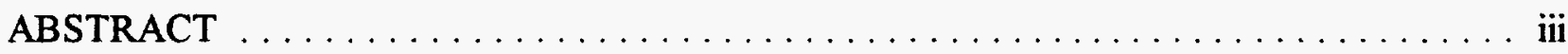

LIST OF FIGURES $\ldots \ldots \ldots \ldots \ldots \ldots \ldots \ldots \ldots \ldots \ldots \ldots \ldots \ldots \ldots \ldots \ldots$

LIST OF TABLES $\ldots \ldots \ldots \ldots \ldots \ldots \ldots \ldots \ldots \ldots \ldots \ldots \ldots \ldots \ldots \ldots \ldots \ldots$ vii

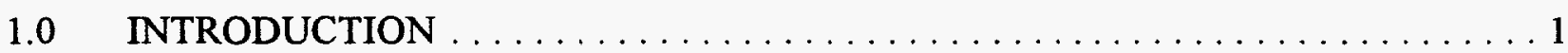

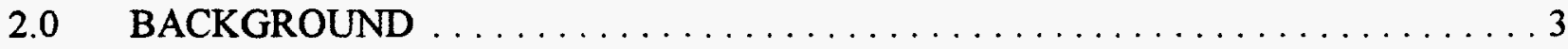

3.0 TECHNOLOGY TRANSFER AND COMMERCIALIZATION ACTIVITIES $\ldots \ldots .7$

4.0 EVALUATIONS OF FQI PROTOTYPE $\ldots \ldots \ldots \ldots \ldots \ldots \ldots \ldots \ldots \ldots \ldots$

$4.1 \quad \begin{aligned} & \text { Cooperative Field Study with Canada Mortgage } \\ & \text { and Housing Corporation } \ldots \ldots \ldots \ldots \ldots \ldots \ldots \ldots \ldots \ldots \ldots \ldots\end{aligned}$

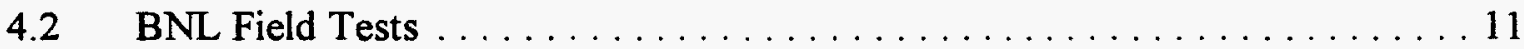

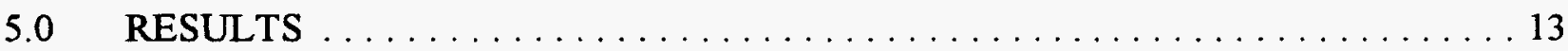

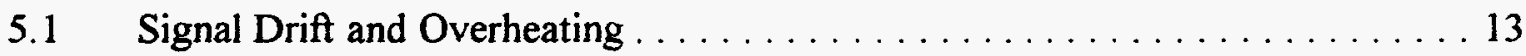

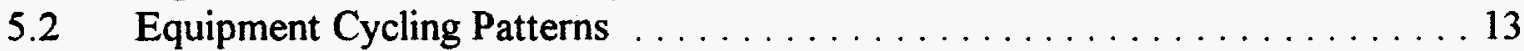

5.3 Response of the FQI to Cycling Patterns in Different Equipment . . . . . . . 16

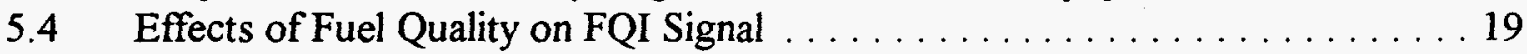

$5.5 \quad$ Long-term Field Tests with FQI Prototype ................... 24

$5.6 \quad$ Field Tests with Industry-Manufactured Prototype $\ldots \ldots \ldots \ldots \ldots \ldots$

5.7 A Summary of Factors That Can Cause a "Red Light" . . . . . . . . . . . . . 39

6.0 APPLICATIONS OF FQI ON MODULATING OIL-FIRED HEATING SYSTEMS . 41

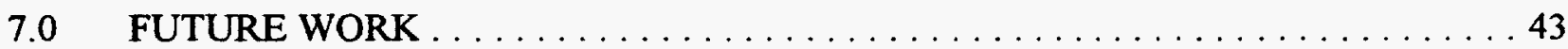

8.0 DISCUSSION AND CONCLUSIONS $\ldots \ldots \ldots \ldots \ldots \ldots \ldots \ldots \ldots$

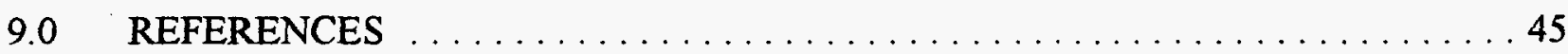

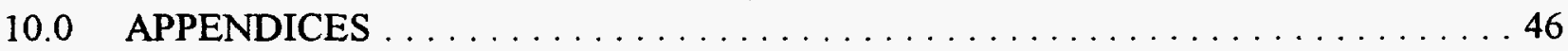
Appendix I: DOE Patent Appendix II: DOE Patent Availability 


\section{LIST OF FIGURES}

Figure 1. Schematic of the BNL Flame Quality Indicator $\ldots \ldots \ldots \ldots \ldots \ldots \ldots \ldots$

Figure 2. Illustration of FQI Response to Changes in Excess Air and Smoke Number . . . . . 5

Figure 3. BNL Flame Quality Indicator and Manufacturers' Prototypes ............. 9

Figure 4. Illustration of the FQI Signal Trend in Three Different Types of Firing Cycles . . . 15

Figure 5. Illustration of the FQI Signal Trend in a Wet Base, Steel Boiler . . . . . . . . . 15

Figure 6. Illustration of the FQI Signal Trend in a Boiler Installed

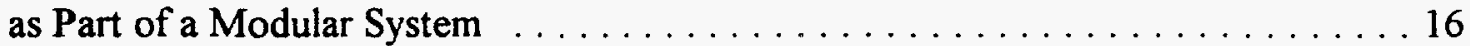

Figure 7. Comparison of Filtered and Unfiltered FQI Flame Intensity Signals . . . . . . . 17

Figure 8. FQI Response During a Heat Call $\ldots \ldots \ldots \ldots \ldots \ldots \ldots \ldots \ldots \ldots \ldots$

Figure 9. FQI Transient Signal - Wet Base, Steel Boiler with Only a Target Wall . . . . . 18

Figure 10. FQI Transient - Wet Base, Steel Boiler with Heavy Refractory Liner . . . . . . . . 20

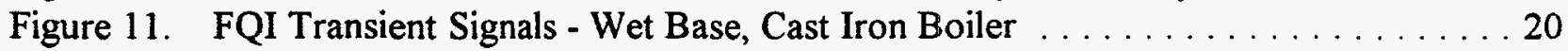

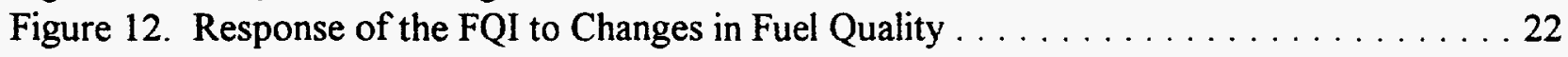

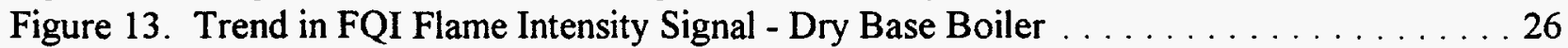

Figure 14. Trend in FQI Flame Intensity Signal - Cast Iron Boiler . . . . . . . . . . . . . 26

Figure 15. Trend in FQI Flame Intensity Signal - Wet Base, Steel Boiler . . . . . . . . . . 27

Figure 16. Trend in FQI Flame Intensity Signal - Boiler No.6 at Nursing Home . . . . . . . . 27

Figure 17. Trend in FQI Flame Intensity Signal - Boiler No. 7 at Nursing Home . . . . . . . 28

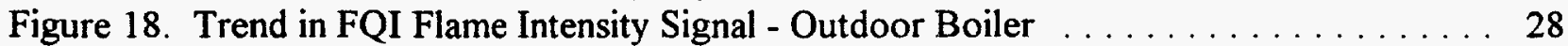

Figure 19. Trend in FQI Flame Intensity Signal - Residence Boiler . . . . . . . . . . . . . . 29

Figure 20. Trend in FQI Flame Intensity Signal - Warm Air Furnace . . . . . . . . . . . 29

Figure 21. Typical Real-Time Data from the OWL ................... 31

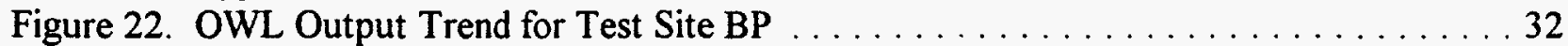

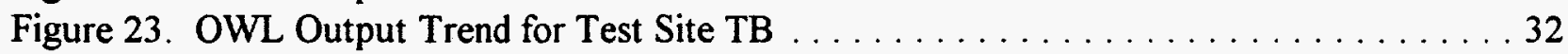

Figure 24. OWL Output Trend for Test Site TP $\ldots \ldots \ldots \ldots \ldots \ldots \ldots \ldots \ldots \ldots \ldots \ldots \ldots \ldots$

Figure 25. OWL Output Trend for Test Site WL $\ldots \ldots \ldots \ldots \ldots \ldots \ldots \ldots \ldots \ldots \ldots \ldots \ldots \ldots$

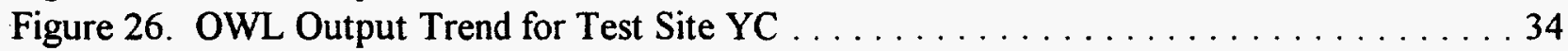

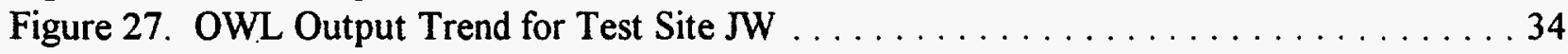

Figure 28. Smoke Number vs. Excess Air at Different Loads - Commercial Boiler . . . . . . 42

Figure 29. FQI Signal vs. Excess Air at Different Loads - Commercial Boiler . . . . . . . . . 42 


\section{LIST OF TABLES}

Table 1. Test Units Included in 1992-93 FQI Test Program . . . . . . . . . . 14

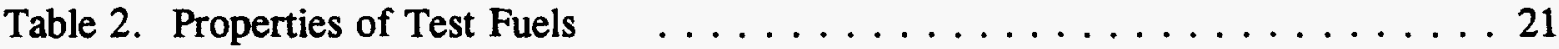

Table 3. Description of Heating Systems at Test Sites with OWL Units . . . . . . 30

Table 4. Factors Which Can Cause a "Red Light" . . . . . . . . . . . . . 40 


\section{$1.0 \quad$ INTRODUCTION}

The Brookhaven National Laboratory (BNL) - Flame Quality Indicator (FQI) is a simple device which monitors the flame of an oil burner by using an optical sensor and control circuit. It uses a conventional cadmium sulfide (CAD) photo-conductive sensor cell to detect any changes in the oil burner flame quality characteristics over time. The FQI device measures and interprets changes in flame brightness and can indicated fuel-rich or fuel-lean conditions when the flame quality is not acceptable. Either of these cases would result in a "Call for Service" condition to be indicated once the flame characteristics (quality) deviates from the established range of acceptable performance. Operation within the preset range is interpreted and indicated by outputting a "Condition Normal, see Figure 1. The burner and FQI must be adjusted, initially, by a qualified serviceman; the FQI then continues to monitor and indicates when something has changed.

The BNL activities in Oil Heat Research and Development during 1987 included the initiation of a project on Advanced Performance Control Strategies to improve the efficiency of small (residential) oil-fired appliances. The patented FQI technology is a direct result of this research and development effort sponsored by the United States Department of Energy (DOE). To date, DOE has licensed the FQI technology to three different private sector manufacturers on a non-exclusive basis. The patent, \#5,126,721 (see Appendix I), is available for license by contacting the Assistant General Counsel for Patents, U.S. DOE in Washington D.C. (see Appendix II).

The first licensed embodiment of the patented technology, called the Oilheat Watchguard Light (OWL) was scheduled by Energy Kinetics Inc. of Lebanon, NJ, for test marketing based on a 100-home field demonstration during the 1993/94 heating season. The second licensed manufacturer, Insight Technologies Inc. of Bohemia, NY (associated with Davis Aircraft Products of Bohemia, NY), announced the general sale and availability of the Insight FQI to the oil heat industry at the May 17-18, 1994 National Association of Oil Heating Service Managers Inc. Trade Show and Convention. The third manufacturer has not yet announced or made public any product development plans based on its application for a patent license. BNL has and continues to provide technical support to all of the licensed manufacturers working on FQI product development.

This report briefly reviews the background and development of the BNL FQI technology, the plans and efforts that followed in transferring the technology to the private sector, and the engineering support provided to manufacturers during product design and commercialization.

The report includes a review of the field tests conducted both in Canada and in the U.S. using the BNL FQI prototype (Section 4), and the results of these tests (Section 5). It discusses the status of the pre-production OWL (FQI) units currently being test marketed in 1993-94, and the status of the Insight-FQI. During the 1993-94 heating season BNL provided technical support to Energy Kinetics by installing and closely monitoring six of the prototype OWL units in homes located in NY and close to the BNL site. The results of this six-home field study are detailed in Section 5.6. 
The current FQI design is generally limited to use on fixed (single) firing rate oil burners. The future of the FQI technology is to develop it for use on step-fired and modulating oil-fired combustion systems and also for use as a burner service diagnostic tool. This would allow the FQI technology to be used on larger oil-fired equipment including large commercial, industrial, and possibly utility boilers and furnaces. Work in this area completed to date at BNL is also briefly summarized in this report.

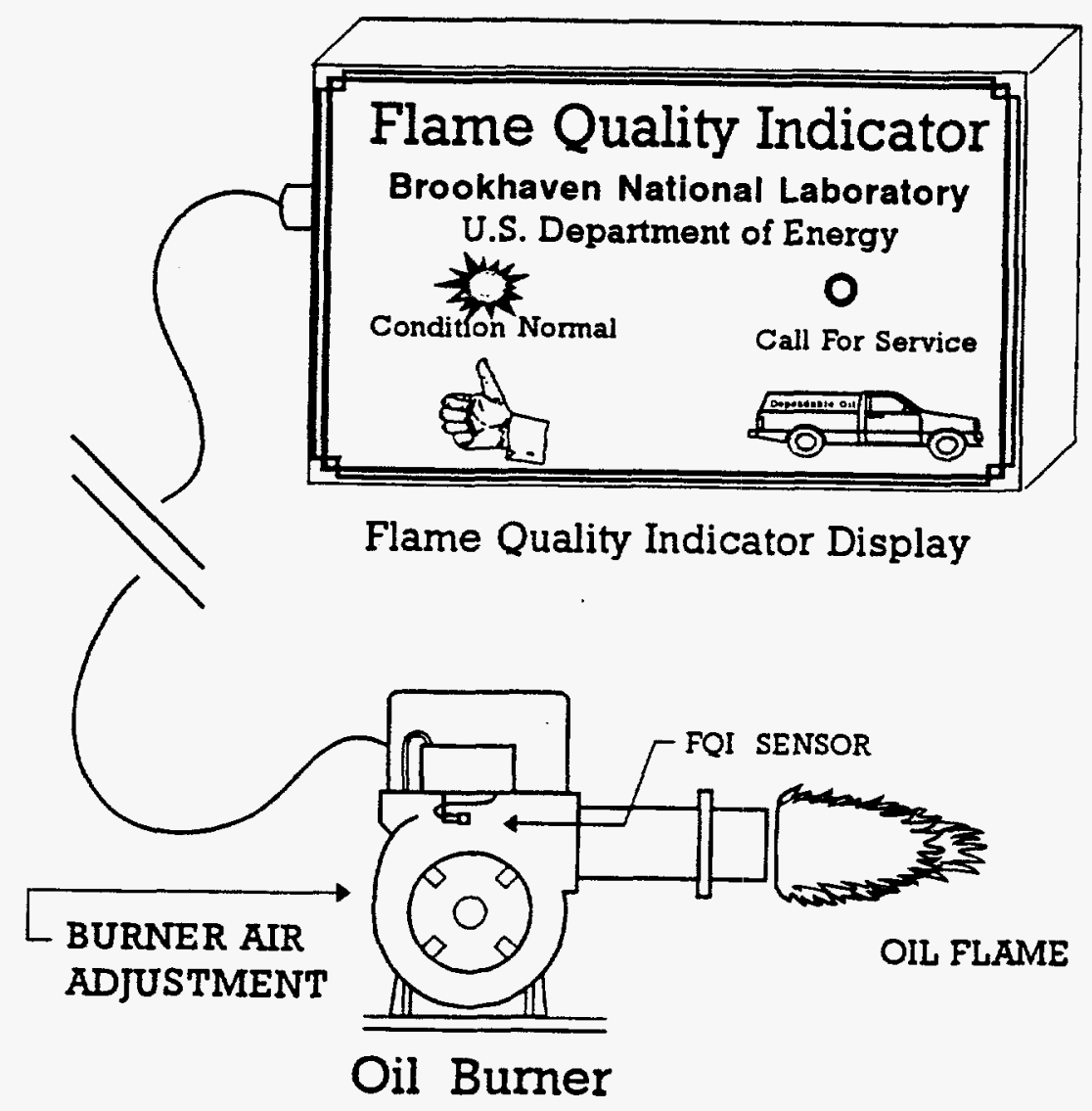

Figure 1 Schematic of the BNL Flame Quality Indicator 
During 1987 a project was initiated to investigate and develop recommendations for control strategies which could be used to raise the efficiency of oil-fired heating equipment used in over 12 million homes in the United States. The adjusted efficiency of oil-fired equipment as found in the home is typically lower than can be achieved with the same equipment under ideal conditions.

Two factor are responsible for the lower than achievable efficiencies. First, when burners are serviced the excess air is set higher than necessary. This is done to allow a margin of protection in maintaining the air/fuel ratio in the fuel-lean condition over long periods of time. The hope being that soot formation will be minimized and service requirements will be minimal as well. Service personnel should always use instrumentation to properly adjust oil-burners to the correct air/fuel ratio, unfortunately, and too often, many do not or can not take the time to do this during every service call. The second factor is fouling of heat exchanger surfaces over time with the products of incomplete combustion, acid deposition, and corrosion products (scale). Less than half of the "soot" deposits cleaned from fouled heat exchangers are actually carbon based material (related to fuel which is not completely burned). During transient burner operation (start-up and shut-down) sulfuric acid condensate from the flue gases reacts with the cast-iron or steel of the boiler (or furnace) surfaces forming iron-sulfate. More than half of the "soot" deposits are actually iron-sulfate deposits formed during this corrosion process.

BNL has investigated several mechanisms to reduce fouling of heat exchangers and the degradation of efficiency that results. The rate of iron-sulfate deposition can be dramatically reduced by limiting the formation of sulfur-trioxide during the combustion process. This can obviously be accomplished by limiting the sulfur content of fuel oil. The changing dynamics of the light distillate fuel supply market in the United States suggest that in the future this might be a viable option. Another option is to operate the oil-burner close to the stoichiometric air/fuel ratio limit. This results in a dramatic reduction in the formation of sulfur-trioxide with existing fuel sulfur levels $(\sim 0.25 \%$ by weight $)$ resulting in a sharp reduction in corrosion and scale formation. One problem with this approach is that it diminishes the margin of protection in maintaining a fuel-lean air/fuel mixture afforded through the use of higher excess-air levels for clean combustion. If a burner is set with no margin of excess-air, any reduction in the air supply will result in a degradation of the flame quality and increased formation of carbon based "soot" which in turn contributes to the rate of fouling and efficiency degradation over time.

In analyzing this situation BNL considered two benefits that a flame quality indicator (FQI) could provide. First, such a system could be used as a monitor alerting the user of changes in flame quality conditions that are precursors to degraded system performance. This monitor would, in the event of changes that would lessen performance, provide an early warning that service is required to maintain efficiency and/or prevent the situation from degrading to the point that a flame failure would occur resulting in a flame safety lockout. The undesirable result of a flame failure is a "no-heat" call by the homeowner to the oil marketer or service technician requesting immediate remedy of the problem. The benefits of scheduling a service call well in 
advance of the "no heat" call include increased efficiency performance over long periods of time, increased customer satisfaction, and reduced maintenance and service costs associated with a system that becomes fouled with "soot" requiring extensive disassembly of the heating unit and brushing and vacuum cleaning of the heat exchange sections.

The second benefit considered was that the FQI could allow the service technician to set the excess air level much closer to an ideal level (minimum) resulting in reduced sulfuric acid formation and the associated corrosion that contributes so heavily to heat exchanger fouling. This would be possible because of the FQI's ability to provide an early warning when things go out of adjustment as discussed above. This eliminates the need for the large amounts of excess air that service technicians currently use to provide a margin of protection in the burner's air/fuel setting to prevent no-heat calls. The proper air/fuel setting would be expected to result in much longer periods (possibly double) between heat exchanger cleanings while also having the positive benefit of increasing the efficiency by reducing losses up the chimney related to excess air.

A wide variety of systems which control air/fuel ratio are commonly used on commercial, industrial, utility boilers. Current practice and experience in this area provided a base for BNL for considering such systems for smaller residential systems. These larger systems typically react to wide variations in load and modulate firing rate accordingly. To maintain high levels of efficiency throughout the range requires that the control systems function to vary the air/fuel ratio over the load range, increasing combustion air as firing rate increases to avoid smoke formation. The available control systems utilized several alternative mechanisms for this purpose including preset air/fuel ratio profile (requiring extensive initial set-up measurements), feed forward oxygen based trim, oxygen feedback, and combined oxygen and carbon-monoxide feedback. These options were all investigated by BNL in detail. The cost and complexity of these options precluded their use on small residential heating systems.

The available literature used in designing combustion system controls includes emerging technologies based on flame spectral detection tied to performance characteristics on large systems such as utility boilers. BNL undertook tasks to investigate the spectral emissions of small residential oil-burner flames to see if this would provide a basis for developing a system for monitoring the flame quality. The approach to the control would be to monitor one or more wavelength bands and this would be used as an indicator of flame quality. In a very rough sense it is an extension of the old oil heat industry practice of observing the flame to determine color. Fuel-rich flames correlate with a dull orange color and fuel-lean flames appearing a brighter yellow color. Various research and development groups have investigated the use of relatively wide flame color bands as an indicator of flame quality for larger combustion systems with promising results. The most difficult problem being that all of these larger systems modulate the size of the flame based on load demands and broad band spectral emissions depend on both firing rate and excess air level.

In residential heating systems the burner is only designed to fire at a single fixed firing rate. To change firing rate, a service technician must remove the oil burner nozzle and install a new one and then readjust the air/fuel ratio manually. This disadvantage in changing firing rate 
is a big advantage in designing a flame monitor that detects flame quality. Given that the flame will be approximately the same size and shape every time the burner fires, an approach can be used based on the broad band flame spectral emissions or "brightness" of the flame. This coupled with a low cost sensor is the basis of the BNL FQI.

The FQI consists of a CAD cell flame sensor, an electronic circuit that interprets the CAD cell output signal based on pre-established ranges of acceptable variations in signal that correlate with changes in flame quality, and an output device that can be as simple as an indicator light that announces a "Call for Service" condition exists. The selection of the setpoint voltage is arbitrary, based on the desired sensitivity, but the FQI functions are only initiated after the burner is first adjusted to its optimum operating conditions and then the baseline voltage is established as the reference point by which all subsequent voltage signals are compared. This provides a measure of the changes in flame quality and therefore the heating system performance. The upper and lower limits were set up based on empirical data. Figure 2 illustrates an example of the typical response of the FQI to burner performance of a residential heating system. The flame intensity signal of the FQI was measured as a function of both excess air and smoke number. This prototype was set up such that a decreasing voltage signal output indicates reduced flame brightness. This data was obtained for a modern flame retention head burner firing into a wet base, steel boiler. The setpoint was established at an excess air level of $30 \%$ at 2.5 volts. Operating this system at below 2.15 volts or above 2.65 volts will trip the FQI and a "red light" or "Call for Service" would be indicated. This corresponds to $40 \%$ excess air and $22 \%$ excess air (Smoke No. 1) respectively.

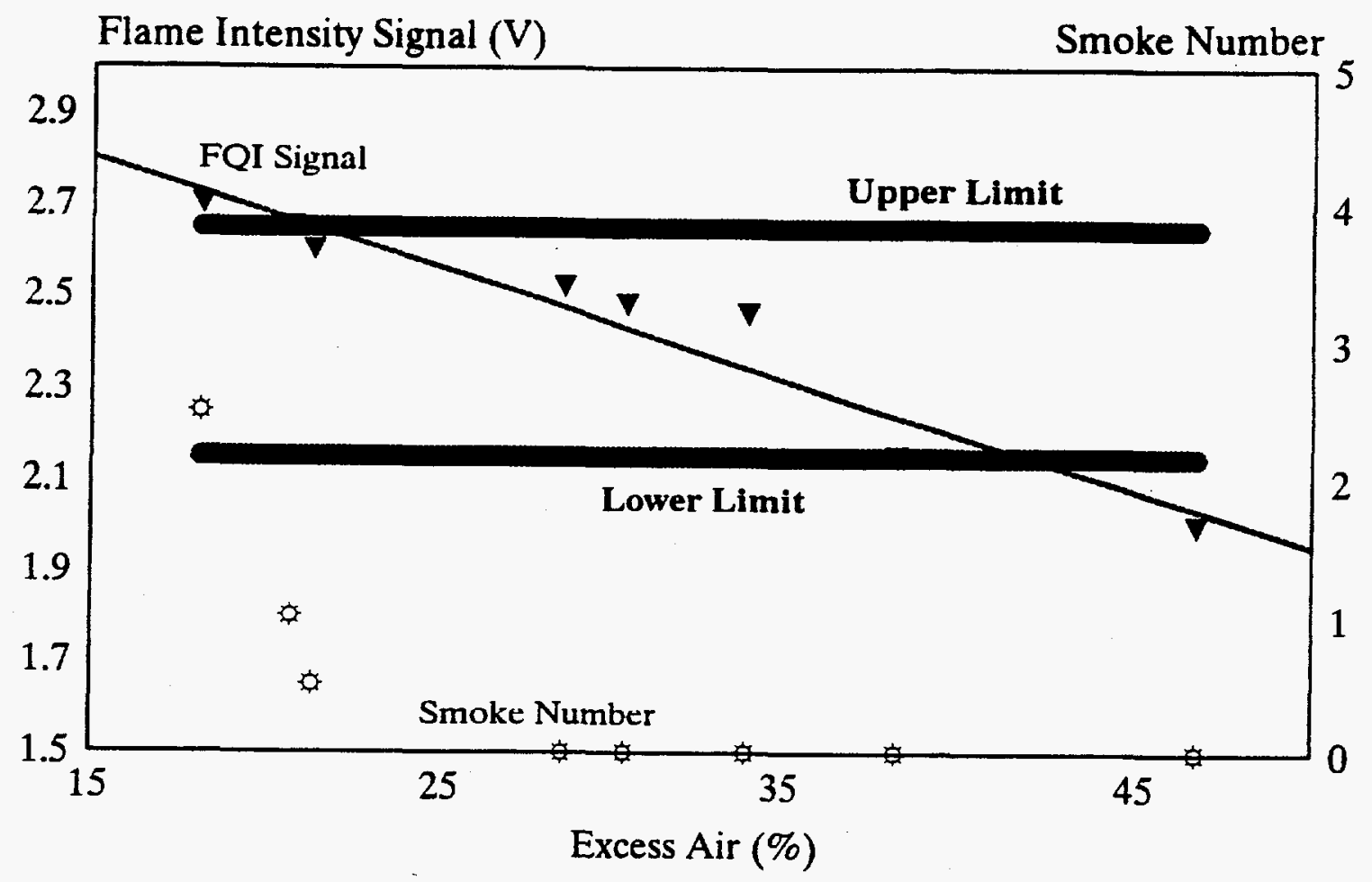

Figure 2. Illustration of FQI Response to Changes in Excess Air and Smoke Number. 
The products to be designed based on the patented FQI technology were intended to be relatively low cost. This was a primary criteria in its development from the beginning. The final level of design sophistication and non-technical market factors will have a large impact on the final price upon product introduction to the market. There are many levels of complexity that can be considered in the embodiment of the concept in a specific product design to enhance its usefulness and/or marketability. These include lights to indicate fuel-rich versus fuel-lean conditions, a "green" light to indicate that the burner is functioning normally, analog or digital outputs to indicate how far off the initial set point the system is operating at, verbal message flags, and even automatic phone dial systems to transmit the signal status back to a oil heat service department's computer. 


\subsection{TECHNOLOGY TRANSFER AND COMMERCIALIZATION ACTIVITIES}

The details of the BNL investigations into alternative control approaches were first reported by Butcher in the Proceedings of the 1989 Oil Heat Technology Conference and Workshop [1] and in the BNL project report, Performance Control Strategies for Oil-Fired Residential Heating Systems [2]. The first experimental prototype FQI was demonstrated at the 1989 conference and was quite successful in showing the potential advantages to the participants at the conference. An operating oil burner was set up so that the participants could manually adjust the amount of air supplied to the burner and observe the FQI response.

The successful demonstration at the 1989 conference was the basis for discussions with the Canada Mortgage and Housing Corporation (CMHC) concerning extended field trials to be conducted both in Canada and the United States during the 1990-91 and 1991-92 heating seasons. A joint venture between BNL and CMHC evaluated the ability of three different burner diagnostic sensors including the FQI, an oxygen sensor, and a net stack temperature measurement concept. The results of the FQI tests are summarized in Section 4.1. The positive results of these tests provided a firm basis for continuing the development of the FQI technology. The results were presented by Sinha of CMHC as part of the Proceedings of the 1991 Oil Heat Technology Conference [3]. At this conference an improved version of the prototype FQI was demonstrated.

To ensure a successful program BNL and DOE initiated commercialization activities that involved oil heat equipment manufacturers, service organizations, and oil heat marketers in the development of a final, marketable product. A work plan was developed that included three primary options for product commercialization of the FQI. The first was a stand-alone FQI which could be readily installed in the field on any burner type. The second was an FQI that would be integrated with a complete boiler or furnace system. The third was an FQI that would be part of an advanced primary safety control using one CAD cell for sensing the flame for both functions.

Twenty prototype stand-alone FQI units were built by BNL and provided to interested industry members for further evaluation.

The first manufacturer in the oil heating industry to show active interest in the FQI was Energy Kinetics Inc., a hydronic boiler manufacturer. Energy Kinetics has combined in their System 2000 integrated appliance product line, a low-mass thermally purgeable boiler, a boilerwater to domestic-water heat exchanger, an insulated storage tank for domestic hot water, along with a System Manager controller. Energy Kinetics worked with BNL to integrate the operation of a prototype FQI to function with the System Manager. The FQI unit was electrically powered by the System Manager and the output signal of the FQI was in turn sampled by the System Manager at a single fixed point in time during the burner firing cycle. In this manner the System Manager would ignore short firing cycles. The FQI which evaluates the flame brightness at the end of each firing cycle can produce a false alarm signal if the system does not have sufficient time to approach full operating temperature conditions. The flame in turn will not reach the brightness level associated with the higher temperature conditions. The design of the System Manager allowed Energy Kinetics to sample the FQI signal only when the firing 
period was long enough to avoid false alarms associated with short cycles and low temperatures. This system was successfully field tested during the second half of the 1992-93 heating season.

Energy Kinetics was the first organization to receive a DOE patent license and developed the OWL in 1993. The OWL has its own microprocessor and is entirely independent of the System Manager controller (Figure 3). This unit can be installed on any boiler or furnace, not just the Energy Kinetics System 2000. The OWL unit incorporates the microprocessor circuit with a simple set of front panel indicator lights, inputs for power and cad cell connections, and output connections to be used to activate a remote alarm (or indicator light), a phone linked heating system monitor, or even a burner shut-off relay if desired. Energy Kinetics initiated a field evaluation of 100 units during the 1993-94 heating season and supplied BNL with several units for field tests in New York. BNL installed six of the OWL units in homes owned by BNL staff who agreed to participate in the field study of the pre-production OWL prototypes.

During the latter part of 1994 Insight Technologies (under the second DOE patent license agreement) completed production of 100 Insight FQI units (Figure 3). This unit also uses an additional, conventional CAD cell which operates independently of the oil burner's primary control to continuously monitor flame brightness. The display consists of lighted indicators that provide real-time sensor status. If the sensor is out-of-range one of the lights indicates whether the reading is high or low; this could potentially be used as a diagnostic tool by the serviceman. Other features include outputs that allow the Insight FQI to interface with a tank monitoring or security alarm system, or an automatic phone dialer. The Insight FQI operates on 9 volt or 24 volt DC power supply and is unaffected by fluctuations in power or power outage. The initial installation and setup is simplified with an automated set-point adjustment. Insight Technologies has already installed a few pre-production units in homes to get some preliminary data and experience with its operation. Additional Insight-FQI units are in production and are marketed to the oil heat industry.

Commercialization of FQI is moving ahead rapidly with two companies already working on product development and test marketing. BNL is currently supporting these private sector development efforts by providing background information, design assistance, and co-operating in field testing of pre-production prototypes, and promoting the technology within the oil heat industry. 

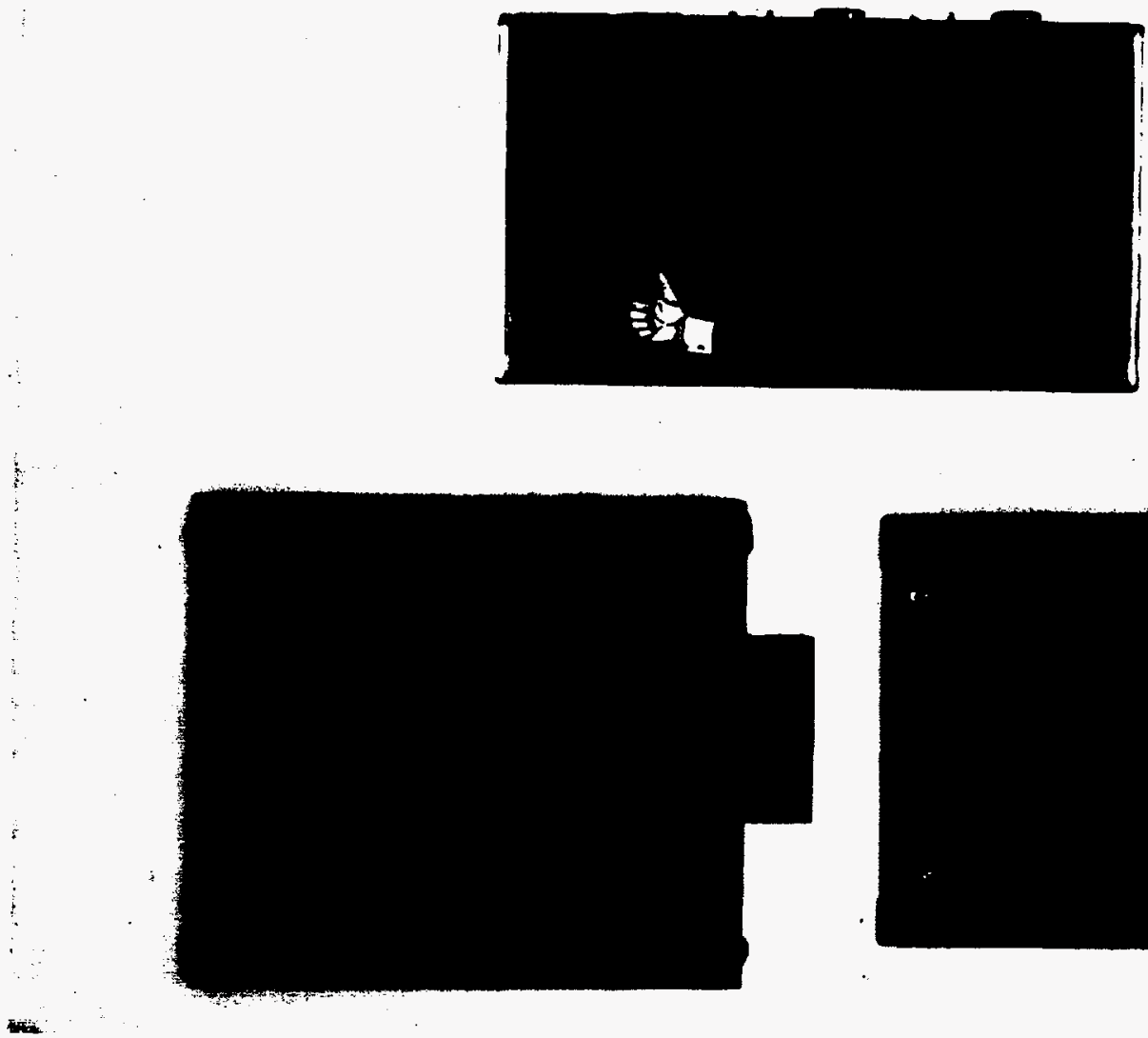

Figure 3. BNL Flame Quality Indicator and Manufacturers' Prototypes. 


\subsection{Cooperative Field Study with Canada Mortgage and Housing Corporation}

During the 1989-90 heating season field tests of the FQI prototype system were started both in Ottawa, Canada and in New York. All of the work in Canada was done in cooperation with BNL under the sponsorship of the Canada Mortgage and Housing Corporation (CMHC) and was implemented by their contractor - Buchan, Lawton and Parent LTD. In parallel with the tests in Canada BNL conducted additional field and lab tests to support this effort. The results of the BNL work was presented by Butcher in 1991 [4].

Much of the residential heating requirements in the colder, remote regions of Canada are met with oil-fired equipment. In such areas, fuel and service costs are high. Thus, maintaining heating equipment at optimum efficiency is especially important in these markets as it can minimize unnecessary costs associated with poor heating equipment performance.

All field installations occurred during late February of the 1989-90 heating season. The 1989-90 heating season ended in May, and the 1990-91 heating season spanned from October 1990 through to the end of April 1991. Throughout the nine months of monitoring, the FQI in all installations were in continuous operation. No service was provided before the fall 1990 start-up, as burner failures and heat exchanger fouling were desired so that the FQI's ability to detect these problems early, before major failures occurred, would be tested.

CMHC found, in general, that the FQI performed very well. At all sites the FQI signal was seen to track the carbon dioxide $\left(\mathrm{CO}_{2}\right)$ content of the stack gas, and generate valid alerts when the $\mathrm{CO}_{2}$ excursions were large enough, when the burners actually required service. In addition, the FQI sensor was able to detect and signal pump failures on two sites and on a third site the FQI correctly signalled a clogged nozzle. Upon replacement of the pump and motor and recalibration of the FQI, the FQI signal returned to an acceptable value and remained stable. This was confirmed by two $\mathrm{CO}_{2}$ measurements conducted following the service call.

Clearly the FQI has potential advantages in indicating or predicting burner operating problems. However, CMHC's monitoring program did reveal some conditions when the FQI gave false alarms or when the FQI was not functioning as expected. These concerns included initial signal drift, handling of short cycles, sensor overheating and signal changes due to oil deliveries. Additional laboratory and field support tests at BNL which continued into 1992-93 identified solutions to these concerns, which are presented in Section 5.0.

FQI signal drift was found to occur over an extended period of time and several factors were found to cause this. The CAD cell's operation was found to be strongly affected by excessive heat and the cell must be mounted accordingly to prevent permanent damage. The initial change in the optical reflectivity of a brand new oil burner air tube was 
also identified as a concern. The interior metallic surfaces are, at first, bright and shiny as manufactured in the factory, but quickly tarnish reducing the internal reflectivity. It was found that coating the interior surfaces with flat black paint reduced these changes. During the 1992-93 heating season BNL conducted another field study to validate that the modifications developed in the laboratory would be effective in the field. This study provided additional information and experience in the field which was very important in demonstrating the value of the FQI to the oil heat industry and manufacturers interested in licensing the technology.

\subsection{BNL Field Tests}

During 1992-94 emphasis was placed on continued field testing as well as supporting the commercialization of the now patented FQI. For any device, like the FQI, to be practical it must be able to respond to a very wide variety of systems. BNL initiated a longterm field study during the 1992-93 heating season with the primary objective of evaluating the operation of the FQI with different heating system types, to identify further FQI improvements based on this work, and to address the concerns identified in the previous CMHC study. In selecting the units for these tests BNL attempted to cover most of the types of systems which would be encountered in the field. All of the units were carefully monitored for basic behavior as well as FQI trends. For some of these sites BNL installed remote data acquisition/monitoring systems. In other cases data acquisition equipment was used at the site only on a periodic basis. Analyzing the FQI signal trends allowed for the evaluation of stability and reliability of the design.

As a result of this work, FQI signal drift problems were greatly reduced. In addition, fundamental analyses were done to determine other factors affecting the operation of the FQI including equipment cycling patterns, flame intensity with respect to time over a heating cycle, response time of the FQI to monitor flame quality, and the effects of fuel properties on FQI signals. The details of this study were presented in 1993 [5]. A summary of the findings from these tests are covered in Section 5. The results of the field work also demonstrated that the FQI could successfully identify service required situations such as partially blocked burner air inlet, nozzle fouling, partially blocked fuel line, and poor ignition.

The field test conducted by BNL during 1993-94 directly supported Energy Kinetics in its evaluation of their OWL flame quality indicator. The objectives of the field test were to provide technical support and independent evaluation of any unexpected problems to maximize the potential for a successful outcome and to obtain important practical data which contributed to the development of advanced controls of this type. All test were done using the new OWL system. Specifically, BNL included in its tasks:

* BNL Field Tests At six local sites, BNL conducted controlled tests to closely monitor the performance trends of the OWL units. Data acquisition equipment were used at 
these sites and regular inspections visits were made. The results of these findings are covered in Section 5.6.

* Technical Support to Energy Kinetics BNL prepared recommendations for starting the tests, periodic inspections, responses to fault conditions, and inspections at the end of the tests. These recommendations were designed to provide the maximum opportunity to diagnose unexpected situations. Portable data acquisition equipment were provided to Energy Kinetics and data were monitored by BNL. This was done remotely by modem to track the performance of the selected sites and to return reports as appropriate to Energy Kinetics. As unusual occurrence were noted at test sites BNL worked with Energy Kinetics to plan responses.

* BNL Lab Tests BNL performed special tests at its Combustion Equipment Technology laboratory to analyze unusual situations as appropriate.

As BNL field testing continued during 1993-94 support for commercialization efforts was provided to Insight Technologies and other interested organizations. The Insight FQI was not yet available during the 1993-94 heating season for field testing.

The BNL study consisted of closely monitoring the performance and reliability of the units installed at six local sites. Data acquisition equipment were used at these sites and regular inspection visits were made. At the start of the project basic information were obtained from each site related to equipment type, current condition, and operations. Setup of the heating system operating conditions, excess air, cad cell installation, and the OWL signal adjustments were done according to a consistent set of procedures. Routine monitoring procedures were also prepared for the participants or the homeowners.

Data collection and monitoring for each site consisted of three main steps: (1) collection of baseline information on equipment and operations through site visits; (2) routine monitoring of stack gas oxygen content, smoke number, any failure or service-needed alerts as indicated by the OWL units; and (3) routine data acquisition and analyses. Data was collected on portable dataloggers (manufactured by ACR Instruments, Inc.) which record voltage output signals from the flame quality indicator. Routine analyses meant that when the flame quality indicator was preset at the optimum voltage signal (2.5 volts), any drift in this signal was tracked, and trends were evaluated to determine when operating conditions were changing. These test results are covered in Section 5.6 
This section summarizes the results of all field and lab work performed that are related to the performance and reliability of the flame quality indicator. Each subsection covers those independent factors which have been demonstrated to affect the operations of the monitoring device and were the basis for further improvements and continued development of more advanced designs.

\subsection{Signal Drift and Overheating}

Early in the development and field testing of the FQI there were concerns about signal drift. To some degree the questions of initial drift and overheating were related. Conventional $\mathrm{CAD}$ cells are normally rated for use in environments under $140^{\circ} \mathrm{F}$. In tests with furnaces with the CAD cells located within the air tube, close to the retention head, the cells are exposed to much higher temperatures. In some cases, the cell casings were found to be partially melted. This was not a problem when tests were done with the FQI installed in hydronic boilers. Highest temperatures were observed just after burner shutdown when the sensor was continually heated by radiation from the hot refractory and the combustion air flow, which tends to cool the sensor, had stopped. When overheating occurs the sensor quickly looses sensitivity and the output signal drifts. This problem was effectively eliminated by moving the cells farther back in the air tube, under the ignition transformer.

Another factor which affected signal drift was the collection of small amounts of soot onto the air tube and retention head, and the oxidation of these metal surfaces, which occurs during the first week of operation of a brand new burner. This quickly reduced the initial surface reflectivity. The FQI signal is a function of how much light (flame radiation) is detected by the sensor and is the sum of direct and reflected light. When the reflected light is diminished, by the blackening of the air tube and retention head components, the signal strength drops off. BNL investigated several options to resolve this problem. The most practical solution was to paint the reflective component surfaces of new burners with flat black paint.

\subsection{Equipment Cycling Patterns}

The field study in 1992-93 demonstrated that the equipment cycling pattern is one of the key parameters that affected FQI operation. Three of the boilers tested (test sites DB, WBS1, and WBC shown in Table 1) were in homes that had tankless coils for domestic hot water. These each had three distinct types of burner firing cycles: 1)"standby cycles" where there is no heat call and the burner simply makes up for off cycle heat loss, 2)"heating calls" where the burner fires several times to satisfy a thermostat call and 3)"hot water"cycles where there is a hot water load only. 


\begin{tabular}{|c|l||}
\hline Test Site & \multicolumn{1}{|c|}{ Unit Description } \\
\hline WF & A conventional, high-boy warm air furnace at BNL. \\
\hline DB & A dry base, steel boiler in a home; 14 years old. \\
\hline WBS1 & $\begin{array}{l}\text { A new, wet base, steel boiler in a home. This unit has a refractory wall where } \\
\text { the burner enters but otherwise the flame is exposed directly to the boiler steel } \\
\text { wall. }\end{array}$ \\
\hline WBS2 & $\begin{array}{l}\text { A wet base, steel boiler with a thick refractory liner in the combustion } \\
\text { chamber. Several identical models were included in the test program. Includes } \\
\text { lab tests, tests in homes and tests of a unit which heats a small factory area. }\end{array}$ \\
\hline WBC & $\begin{array}{l}\text { A wet base, cast iron boiler in a home. This unit has a "bucket" type } \\
\text { refractory chamber liner. }\end{array}$ \\
\hline MB & $\begin{array}{l}\text { A wet base, steel boiler used as part of a multiple boiler system in a Nursing } \\
\text { Home near BNL; 2 identical boilers tested. }\end{array}$ \\
\hline
\end{tabular}

Table 1. Test units included in 1992-93 FQI test program

Figure 4 shows a typical $\mathrm{FQI}$ flame intensity signal response over a time period where each of these types of cycles have occurred (unit DB shown, WBS1 is similar). For these tests when the burner was off the FQI flame intensity signal measured 0 volts; when it was on it reached about 2.5 volts. During standby cycles, the burner on-time is about 2 minutes. With hot water cycles the burner on-time varies from about 3 to 10 minutes. Heating call cycles are very repetitive. For the first firing the burner on-time is long, 10-20 minutes. The next firings are considerably shorter, 3-5 minutes. From site-to-site the duration of the burner on-time depends upon the size of the distribution system and the nozzle size. With a high firing rate the burner ontime will, of course, be shorter.

During this program BNL field tested three boilers of the type WBS2 (same model). Two of these are in homes and one provides heat in a factory area. In one of the homes the boiler is slightly undersized and, as a result, the burner runs very often with long burner on-times (to 2 hours). In the other home, burner on-times of 5 minutes are more typical. The factory where the third unit is located has night setback. When the system "picks-up" in the morning the burner has extremely long on-times (to $21 / 2$ hours). A part of the cycling pattern at this site is shown in Figure 5.

The typical cycling pattern for unit MB is shown in Figure 6. This unit has a high firing rate $(2.5 \mathrm{gph})$ and cycles very frequently. The burner on-time never exceeds $21 / 2$ minutes. 


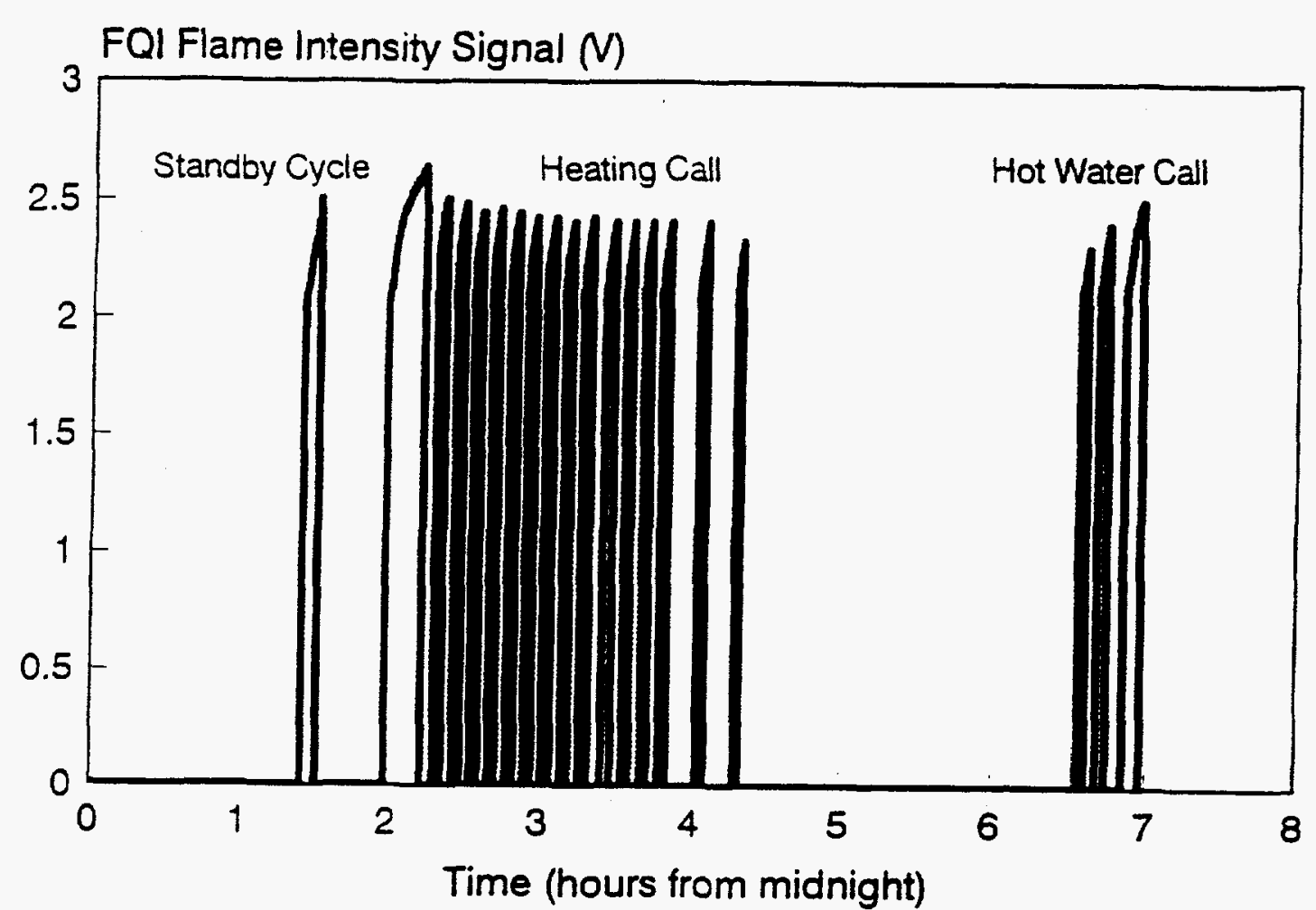

Figure 4. FQI Signal Trend in Three Different Types of Firing Cycles. Unit DB - Residential, Dry Base, Steel Boiler (Filtered Signal).

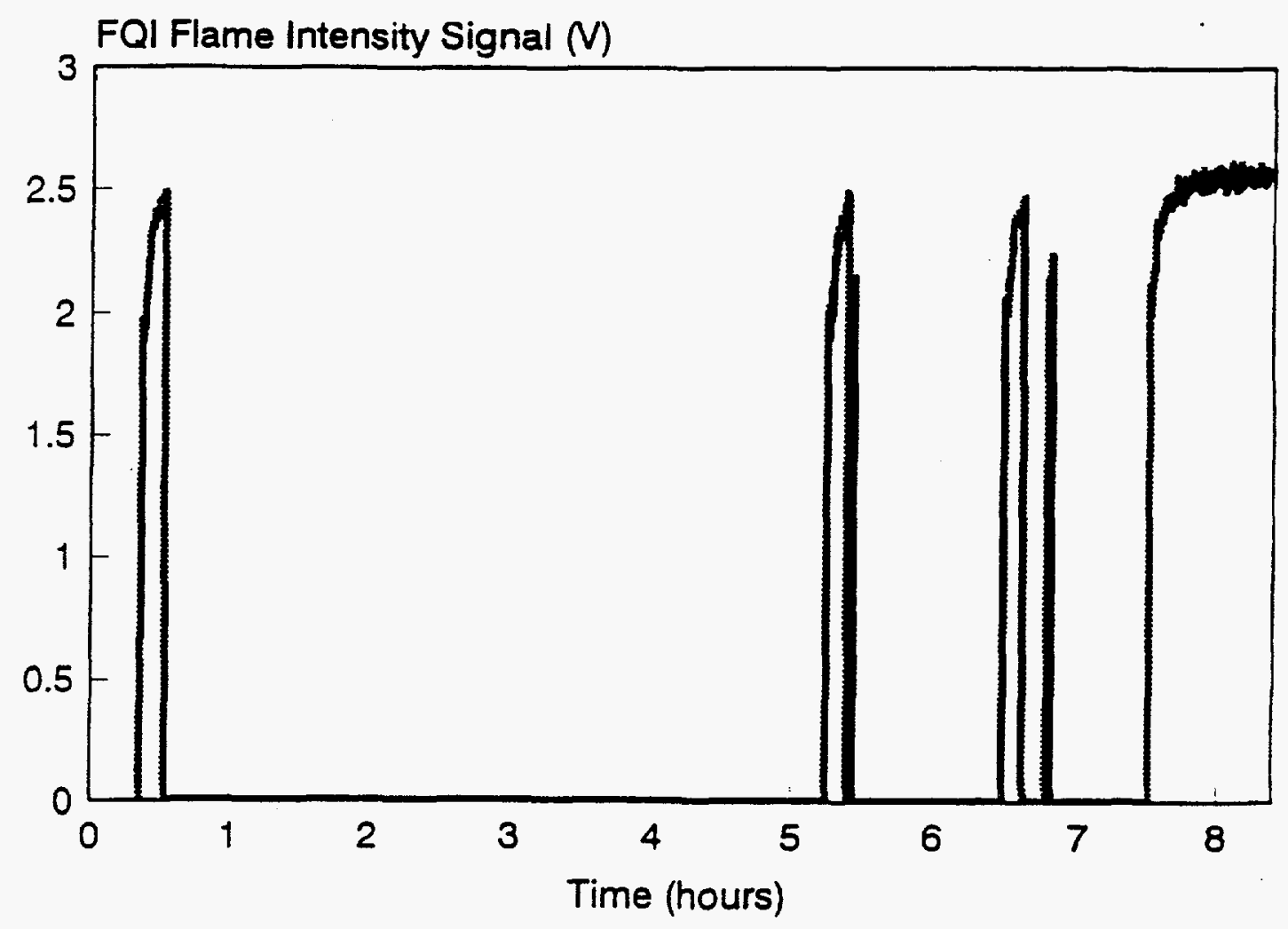

Figure 5. FQI Signal Trend Through the Night/ Early Morning. Unit WBS2 in a Factory - Wet Base Steel Boiler with a Heavy Combustion Chamber Refractory Liner (Unfiltered Signal) 


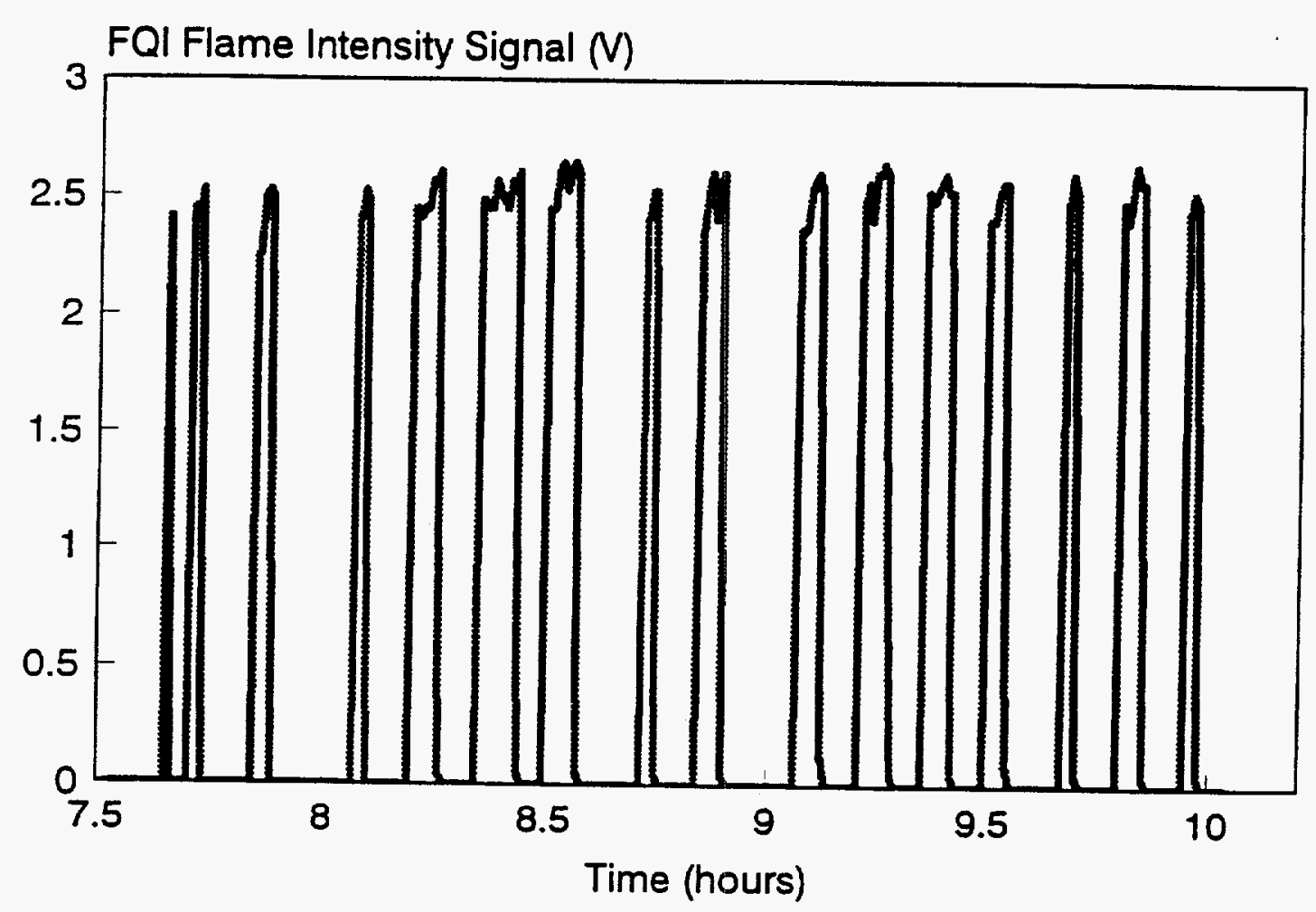

Figure 6. Illustration of the FQI Signal Trend in Boiler Installed as Part of a Modular System in a Nursing Home. Unit MB - Wet Base, Steel Boiler (Unfiltered Signal)

All of the boilers that BNL tested during this project had operating characteristics similar to at least some part of Figures 4 to 6 . While a pattern like that of Figure 6 may indicate a serious case of nozzle over-sizing, the site shown is not the only one where this was observed. The warm air furnace (WF) included in BNL's test program was installed in the BNL lab and operated with an imposed firing cycle. BNL had considerable data on the cycling patterns of different furnaces. Firing times varied considerably and ranged from 2 to 40 minutes.

\subsection{Response of the FOI to Cycling Patterns in Different Equipment}

The first FQI system developed at BNL used the signal intensity at the end of each burneron period to gauge flame quality. This led to an occasional false "red light" condition if the "on" period was very short. Short firing cycles were a concern because the combustion chamber refractory does not reach its full operating temperature, the flame does not reach its steady state brightness level and the cycle ends with the FQI indicating a bad flame. The electronic circuit in subsequent FQI prototypes were redesigned to ignore short cycles, shorter than 5 minutes for example. These two approaches are discussed along with the transient signal intensities in this section.

Throughout this discussion some of the data is presented as "filtered" signals and some as 
"unfiltered". The purpose of the filter in the circuit is to eliminate effects of normal flame flicker and the BNL FQI has always used a filter in the part of the circuit which controls the flame quality lights. The design was then modified to make the filtered signal available for input to a data logger as well as for initial FQI setup. A comparison of both the filtered and unfiltered signals during a start-up transient period is provided in Figure 7.

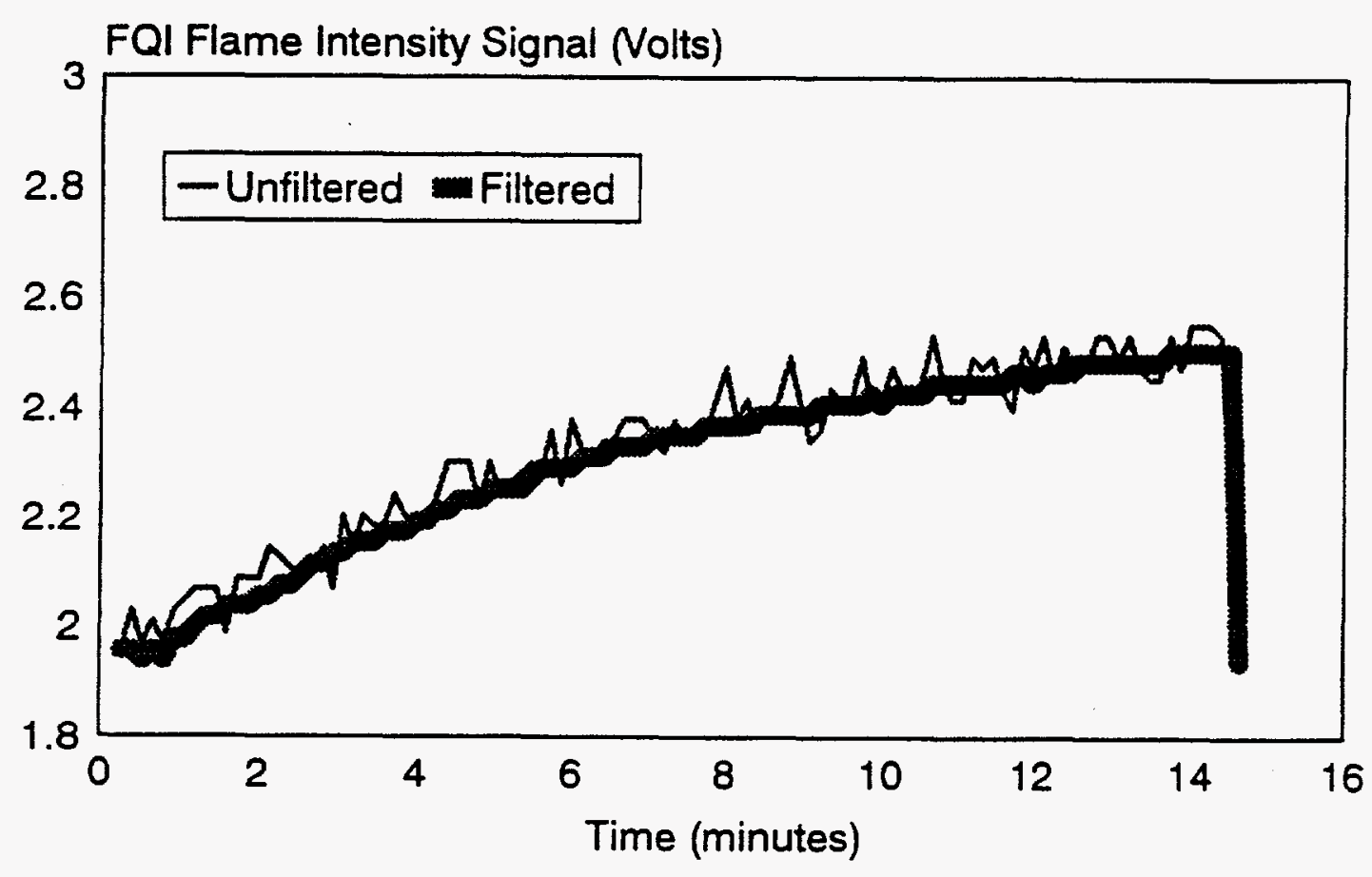

Figure 7. Comparison of Filtered and Unfiltered FQI Flame Intensity Signals - Unit DB.

Generally, the initial transient period is dependent upon the amount of refractory around the combustion chamber. A heavy refractory liner leads to long warm-up time for flame brightness. Figure 8 shows the details of the transients for the dry base boiler, Unit DB, during the seven consecutive burner "on" periods which occurred in response to one typical heat call. The FQI flame intensity signals for each of the seven cycles have been superimposed for comparison. The first time the burner fires, it runs for 15 minutes. After 6 minutes, the signal is nearly at its maximum value although it never really reaches a steady value even after 15 minutes. In the burner "on" periods, which follow the first long one, the initial transients are much shorter. When the burner fires the second time, the refractory is already somewhat hot and this effect makes a difference for flame brightness and the FQI signal.

Figure 9 shows the transient response during one firing cycle with Unit WBS1, which has very little combustion chamber refractory. In this case, the FQI signal shows very little warm-up time. The signal maximum at this site generally occurs early in the firing cycle, as shown in the figure. This may be resulting from warming of the nozzle, which leads to reduced fuel flow, during the "on" period. For this site, with little refractory, this effect is apparently the most 


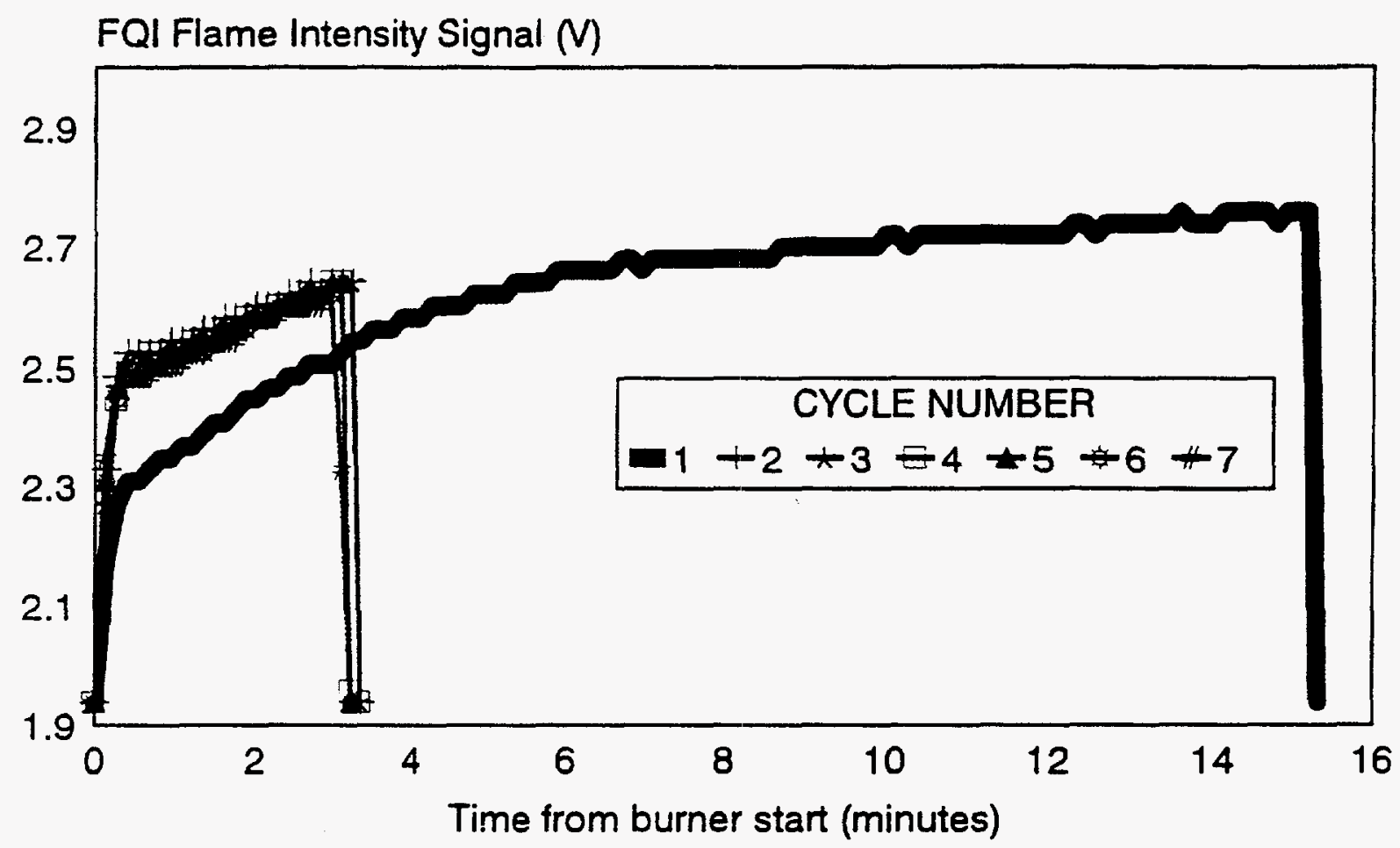

Figure 8. FQI Response During a Heating Call, Unit DB - Residential, Dry Base, Steel Boiler. First Long Burner On-Period Superimposed on Following Short Burner On-Periods (Unfiltered Signal)

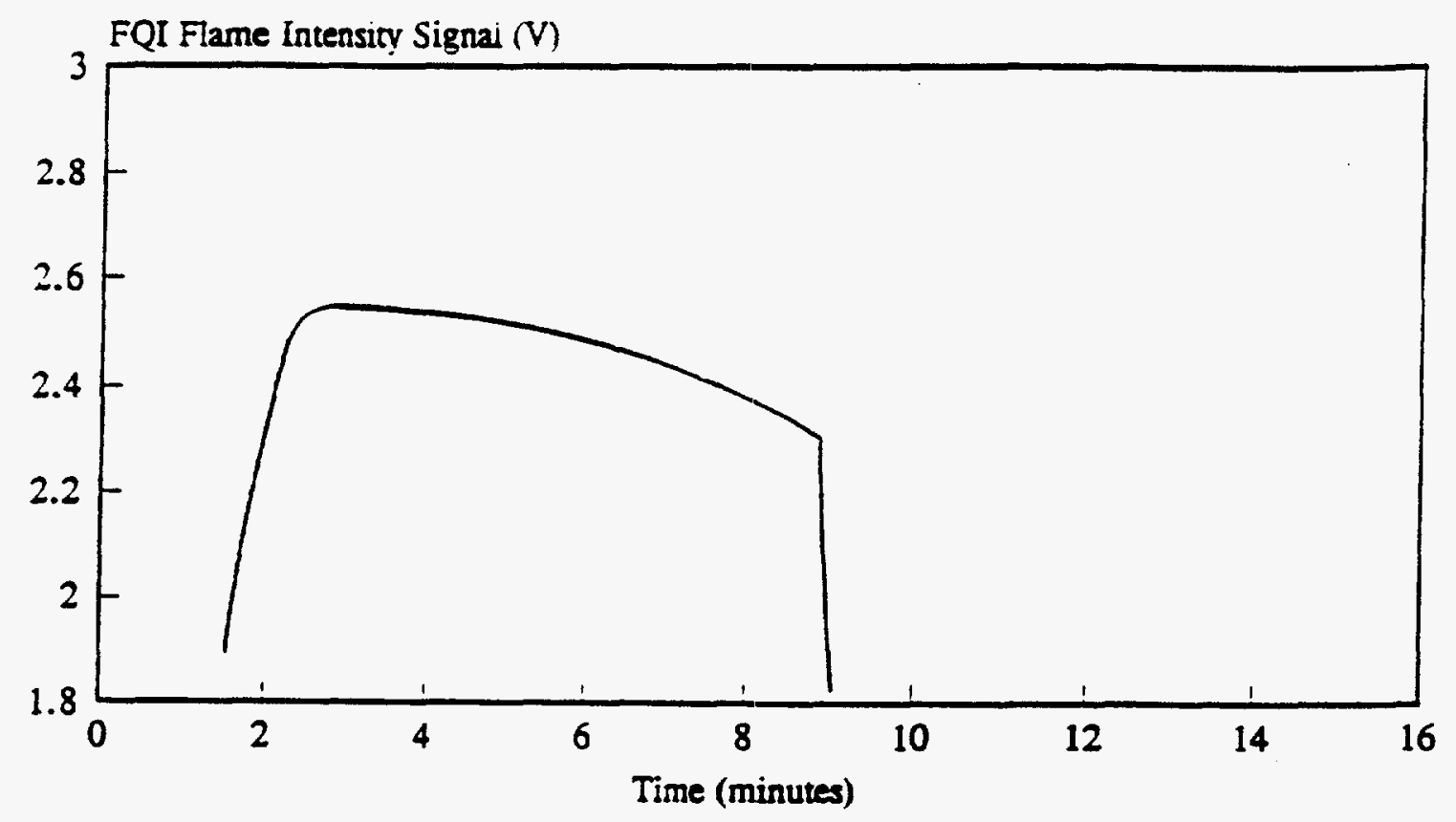

Figure 9. FQI Signal Transient. Unit WBS1 - Wet Base, Steel Boiler with Only a Target Wall in the Combustion Chamber (Filtered Signal) 
important. It may also be occurring at other sites with heavier refractories but at these other sites the refractory effects dominate. At one test site, FQI signals were monitored during a fuel line blockage incident. In this case, the FQI signal and, apparently, fuel flow decreased sharply during the burner "on" period.

The transient response for Unit WBS2 in a home is shown in Figure 10. This unit has a heavy refractory liner and so a long warm up time. After about 8 minutes, the signal reaches a steady value which changes little with firing times as long as 2 hours.

The transient response with Unit WBC is shown in Figure 11. This wet-base boiler has a fairly light refractory liner and a short warm up period. Burner "on" times at this site rarely exceed 4 minutes.

Based on the collection of data, two approaches for designing the FQI signalling method were considered. The first method, which was used almost exclusively in prior tests, sampled the flame quality signal at the end of each firing cycle to control the indicator lights. The second approach examined the FQI signal only at a fixed time after the burner starts. The difference between the two approaches can be illustrated by referring back to Figure 8 . For the seven cycles shown in response to a heat call the FQI signal at the end of the burner on-period is about 2.72 volts after the first cycle and about 2.65 after all of the other cycles - a difference of 0.07 volts. Considering that the acceptable voltage range is 0.50 volts this level of difference seems to be acceptable. This may not be true, however, in the case of a very short isolated cycle where the burner fires only to make-up for off cycle heat loss (no heat call or hot water load). In this case the FQI signal follows the curve for cycle \#1 in Figure 8 but the burner would go off at about 3 minutes. The FQI signal at this point would be 2.5 volts or 0.22 volts less than the end-of-cycle voltage after cycle \#1. A false red light may occur. Considering the second approach the FQI would only evaluate the signal at one fixed time, 5 minutes after burner start-up for example. In this case the flame quality would only be evaluated for the first burner-on period of a heat call or a long domestic hot water draw. All short cycles would be eliminated. A disadvantage of this approach is that the flame quality is not evaluated every cycle. During the heating season a 5 minute cycle might occur only a few times a day. During the summer a long cycle might occur only every few days. While the burner might operate for a few days with a non-critical burner problem this is still a considerable improvement over the typical situation in which the burner might run for months, without a monitoring system, with poor combustion, leading to a fouling problem.

For those cases where the firing rate is relatively high and burner on-times are short the choices are to down-fire where possible, set the time for examining the flame quality shorter (e.g. 3 minutes) or use the first approach of monitoring the signal only at the end of the cycles. If all of the cycles are short (e.g. Figure 6) and the refractory mass is relatively small the end of the cycle approach is acceptable. If the refractory mass is great or a dry base boiler is used the FQI signal changes significantly with time during the first three minutes of burner on-time. The FQI signal at the end of three minutes may be considerably different from the signal at the end of two minutes. 


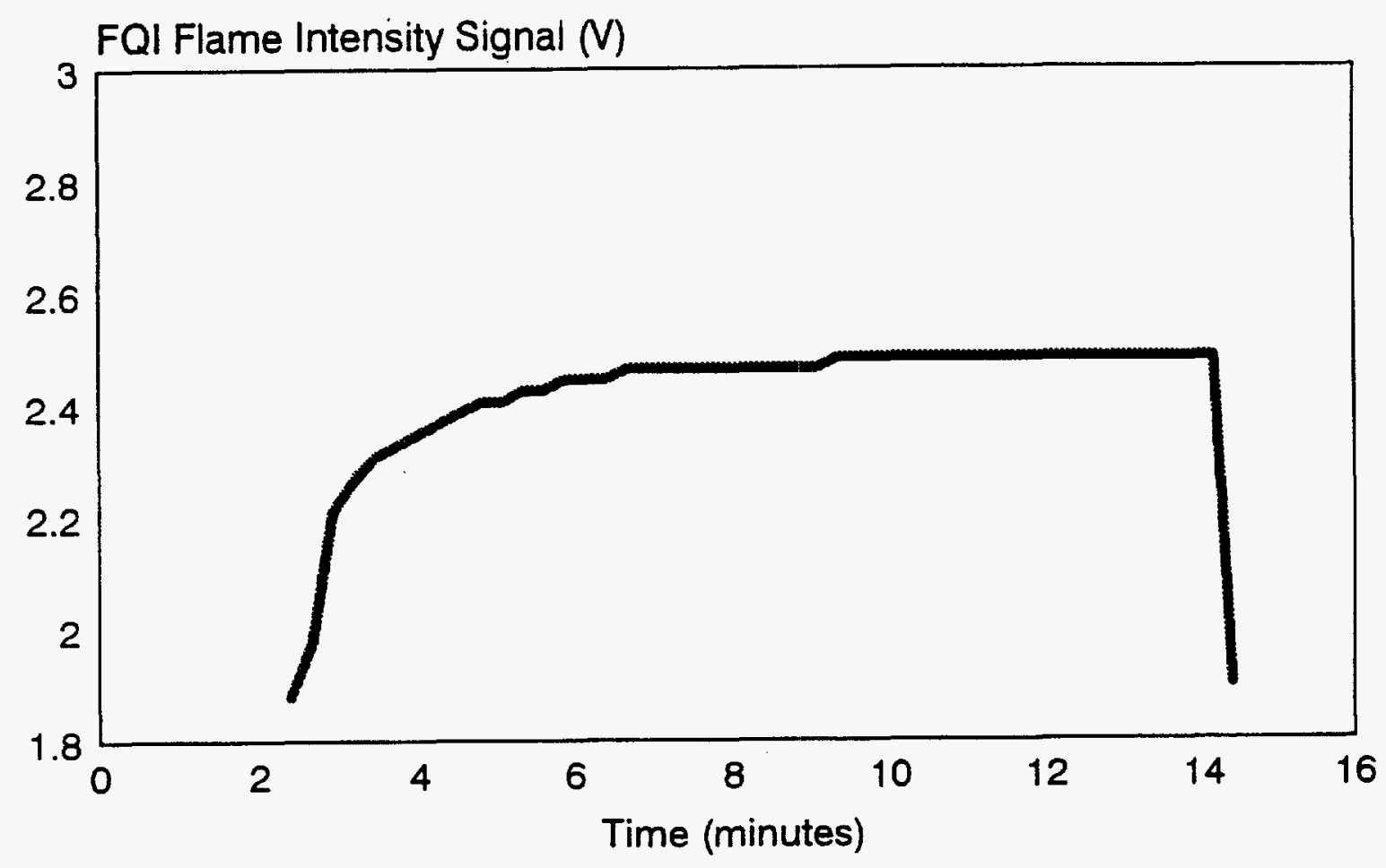

Figure 10. FQI Transient Signal. Unit WBS2 - Residential, Wet Base, Steel Boiler with a Heavy Refractory Liner in the Combustion Chamber ( Filtered Signal)

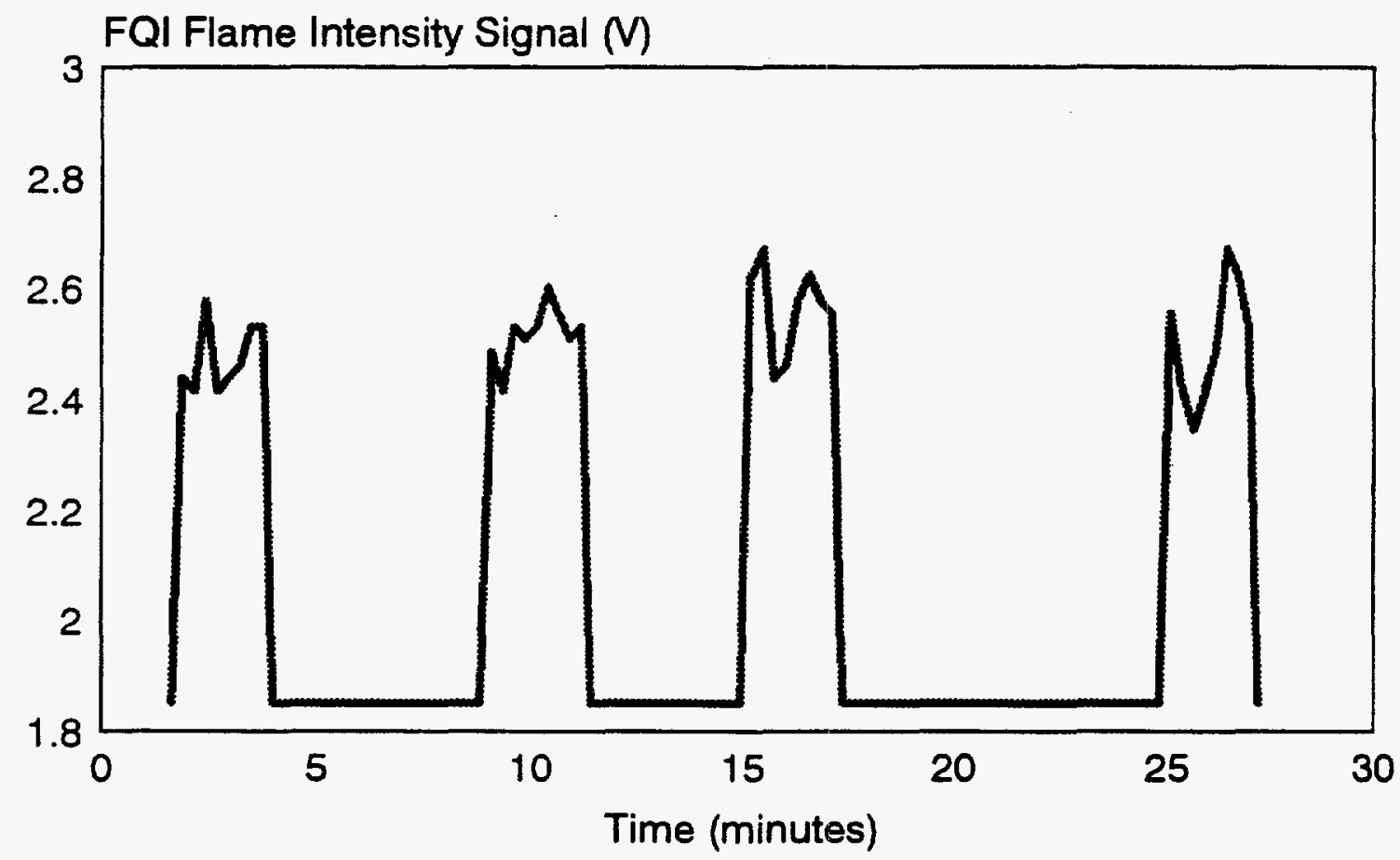

Figure 11. FQI Transient Signals. Unit WBC - Residential, Wet Base, Cast Iron Boiler (Unfiltered Signal) 
For most of the boilers and furnaces tested the use of fixed time sampling, the second approach, would result in much less variation in the signal used by the FQI from cycle to cycle. By reducing this variation it may be possible to reduce the voltage range for the "green light" condition in order to improve the effectiveness of the FQI.

\subsection{Effects of Fuel Quality on FQI Signal}

In long-term use, some questions were raised about changes in the FQI signal following fuel deliveries. One situation that could occur is plugging of the filter or fuel line after a delivery if sludge on the tank bottom is stirred up. Another possible effect would be due to a change in the viscosity and aromatic content of the fuel, which would lead to a change in flame brightness. This effect was not found to be important in field tests probably because changes experienced in fuel quality were actually relatively small. To determine the potential magnitude of problems which could occur, a series of tests were done in the BNL laboratory with a variety of fuels firing in a warm air furnace. Throughout these tests the furnace continued to operate with an imposed cycling pattern and the fuel supply changes were made without any changes to the burner. Table 2 identifies the test fuels and also shows the flue gas oxygen level, the smoke number and the FQI voltage observed when each fuel was fired. The test fuels in the table are listed in order of increasing fuels aromatics content. Of the eight test fuels three do not meet ASTM specifications for No. 2 heating oil. Test fuel No. 2 is off-specification because of the high viscosity. Fuel No. 8 has too low a value for the API gravity. Fuel No. 7 is out of specification in terms of both API gravity and viscosity.

\begin{tabular}{|c|c|c|c|c|c|c|c||}
\hline Number & $\begin{array}{l}\text { Viscosity } \\
\text { (cs@100 F) }\end{array}$ & $\begin{array}{l}\text { Aromatics } \\
(\%)\end{array}$ & $\begin{array}{l}\text { API } \\
\text { Gravity }\end{array}$ & $\begin{array}{l}\text { FQI } \\
\text { Signal } \\
\text { (Volts) }\end{array}$ & $\begin{array}{l}\text { Flue Gas } \\
\text { O2 } \\
(\%)\end{array}$ & $\begin{array}{l}\text { Smoke } \\
\text { Number } \\
\text { in Steady } \\
\text { State }\end{array}$ & $\begin{array}{l}\text { Fuel } \\
\text { Meets } \\
\text { ASTM } \\
\text { Specs }\end{array}$ \\
\hline 1 & 2.6 & 16.6 & 42.7 & 2.18 & 7.0 & 0 & Yes \\
\hline 2 & 5.5 & 33 & - & 2.41 & 6.5 & 0 & No \\
\hline 3 & 1.6 & 33.2 & 38.4 & 2.37 & 8 & trace & Yes \\
\hline 4 & 2.8 & 33.5 & 36 & 2.45 & 6.8 & trace & Yes \\
\hline 5 & 2.3 & 33.6 & 35.6 & 2.43 & 7.3 & trace & Yes \\
\hline 6 & 2.3 & 55.5 & 30.9 & 2.46 & 7.4 & trace & Yes \\
\hline 7 & 8.0 & 76.7 & 27.6 & 2.23 & 5.2 & trace & No \\
\hline 8 & 2.4 & 100 & 14 & 2.83 & 7.1 & trace & No \\
\hline $\begin{array}{c}\text { ASTM } \\
\text { Limits }\end{array}$ & 1.9 to 3.4 & - & 30 min & & & & \\
\hline
\end{tabular}

Table 2. Properties of Test Fuels 
Results showed that fuel Nos. 1, 7 and 8 produced a change in the FQI signal which gave a red light or near-red light condition. In the case of Fuel No. 7, the very high viscosity caused the flame to stand far off from the retention head, leading to a low apparent flame intensity (low FQI voltage). This fuel is very difficult to burn at all in a conventional retention head burner. A red light indication is considered to be a correct response for this fuel.

To illustrate the effects of fuel aromatics content on the FQI flame intensity signal, results of all tests with the exception of the ultra high viscosity test fuel No. 7 are plotted in Figure 12. In the case of Fuel No. 8, the high aromatics content produced a high flame intensity signal. Table 2 lists a trace smoke for this fuel but examination of transient smoke numbers indicated very high start-up smoke production with this fuel. If a fuel like this were used in a home, a red light condition would occur on the FQI. Although test fuel No. 2 is off-specification because of its viscosity, combustion tests showed no adverse effects on equipment performance. The FQI gave a green light condition and this was a correct response. Test fuel No. 1 indicated a low FQI signal because of the low aromatics content. If this fuel were used in a home, a red light condition could occur and this would not be considered a correct response. The aromatics content of this fuel is extremely low, however, based on discussions with refiners it is extremely unlikely that a fuel with these properties could be found in the market. The aromatics content of nearly all No. 2 heating fuel oils is within a narrow range around $35 \%$.

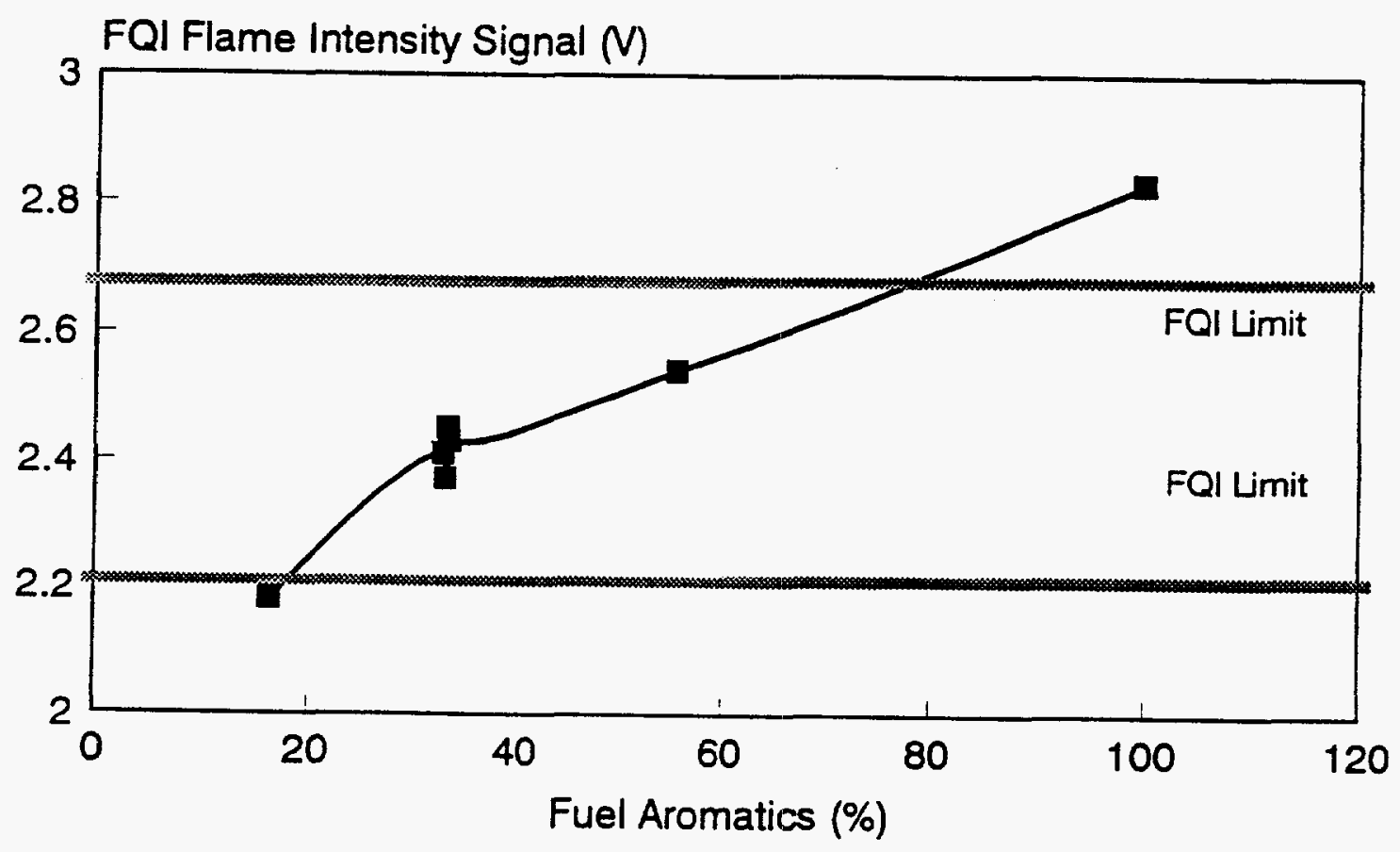

Figure 12. Response of the FQI to Changes in Fuel Quality - Warm Air Furnace in the BNL Lab 
A question was raised on whether the disturbance of sludge during a fuel delivery, which can change the fuel filter flow resistance and the pump suction pressure, could affect the FQI response. To evaluate this effect tests were done with a one pipe fuel system using a throttle valve to simulate varied levels of filter restriction. As fuel pump suction pressure decreased the fuel pump discharge pressure decreased by about the same amount without apparent effects on burner operation until the suction pressure dropped to about 20 inches of mercury $(\mathrm{Hg})$ vacuum. At this level the fuel pump discharge pressure had decreased from $100 \mathrm{psi}$ to about $80 \mathrm{psi}$ and the burner excess air had increased by about $30 \%$ ( 35 to $45 \%$ excess air). Lower levels of pump suction pressure are probably not practical because excessive pump noise signals an obvious problem. With pump suction pressures from 0 to 20 inches $\mathrm{Hg}$, however, the burner could operate without obvious problem. The FQI signal followed the flue gas oxygen content trend. The change in signal over the range was not, by itself, large enough to produce a "bad flame" signal. In one field test "bad flame" signals were produced by a burner with a fuel line blockage problem. This was a severe case however. The FQI warning was ignored and the restriction eventually prevented continuous burner operation and the heating system locked out under the oil burner's primary safety control. 


\subsection{Long-term Field Tests with the BNL FOI Prototype}

Eight long-term tests were conducted in this field study with the BNL FQI prototype. The heating systems included as part of these tests consist of: (1) a warm air furnace at the BNL combustion laboratory, (2) two boilers in a Long Island Nursing Home, (3) two boilers located in New Jersey, and (4) three residential boilers at a site local to BNL. The tests done in New Jersey were a cooperative effort between BNL and Energy Kinetics. One of the units was located outdoors and provided heat to a small factory area, and the other at a residence. Refer back to Table 1 for a description of these test sites. This set represents a good cross-section of appliance types. These sites were very carefully studied to provide useful application data on the FQI.

The trends of the FQI signals for each of the test sites are shown in Figures 13 through 20. A "red light" condition, requiring service, or a drift in the signal was investigated and reported. Note that for these tests flame brightness increases with higher voltage signals. When the burner is off the voltage reads 0 volts and then rises during the on cycle.

Figure 13 shows the trends at a residential site with a dry base steel boiler. At this site there was a very clear drift toward increasing flame brightness, but does not appear to be justified based on measured excess air levels and smoke number. Upon inspection of the nozzle assembly and air tube a considerable amount of oil was found behind the retention head. The burner air tube was found to be tilted backward slightly instead of forwards as the installation instructions call for. The air tube and nozzle assembly were cleaned and the tilt corrected; the signal returned to expected levels. The burner nozzle was not changed. With the oil coating on the air tube the reflectance increased, giving a signal of increased brightness.

Figure 14 shows the trend from a residential boiler - a wet base, cast iron unit. This unit operated without problems or changes during the entire heating season and, as shown, the curve of the FQI performance is essentially flat.

Figure 15 shows the trends at a residential site with a wet base steel boiler. This had shown some downward drift in the FQI signal. Over a period of about a month the homeowner reported consistent red lights. Inspection showed the smoke number to be elevated at this site, from an initial setting of trace level of smoke to a Smoke \#2. A nozzle change, as shown in the figure, brought the signal closer to the setpoint.

Figures 16 and 17 show the trend at the units in the Long Island Nursing Home. Unit No. 6 was inspected and some oil was found in the air tube and some soot on the sensor cell. This was cleaned and the FQI signal responded as shown. The FQI voltage was checked after the cleaning and it was not necessary to make any changes. This system was basically working acceptably. The second boiler, Unit No.7, showed more of a downward 
trend in intensity. This unit apparently had an oil drip problem. The head and air tube were cleaned and the FQI setpoint readjusted.

The trend at the outdoor boiler at the Energy Kinetics plant in New Jersey is shown in Figure 18. This unit consistently showed a very strong downward drift. An inspection of this site was made. The burner top was opened to inspect the sensor and it was found to be dripping with oil. During the visit the CAD cell was simply cleaned until further needed service was done for the unit. The effect on the FQI signal, as shown in the figure, was significant.

The trend in the FQI signal at one home in New Jersey with an Energy Kinetics boiler is shown in Figure 19. The FQI signal has shown only slight drift.

The warm air furnace in the BNL lab was operated under forced cycles - 20 minutes off and 10 minutes on. As with all appliances the flame brightness is relatively low just after the burner starts and increases during the firing cycle. In the case of the furnace the signal approached steady state near the end of the 10 minute firing cycle. The average signal at the end of the firing cycle was used to monitor trends over time. This trend, as shown in Figure 20, indicates that the unit has been very stable for the duration of the 200 days. The nozzle, air setting, and FQI setting were the same at the end as at the beginning of the test. Over $\mathbf{8 0 0}$ gallons of fuel oil had been fired in this furnace.

Laboratory tests were done to evaluate the effects of oil dripping on the air tube on the FQI signal. These tests were done using the warm air furnace which, as previously reported, had been very stable for $\mathbf{2 0 0}$ days of testing. In this test the air tube was lightly coated with fuel oil and then the trends were monitored. During the first on cycle after the coating the flame intensity signal increased greatly. After this first cycle the signal decreased and then became much lower than normal. It seems that for that first cycle the glossy oil coating was increasing the reflectivity of the air tube surface. After the first cycle the oil may have "coked" with heat soakback from the hot combustion chamber, leading to reduced reflectivity. 


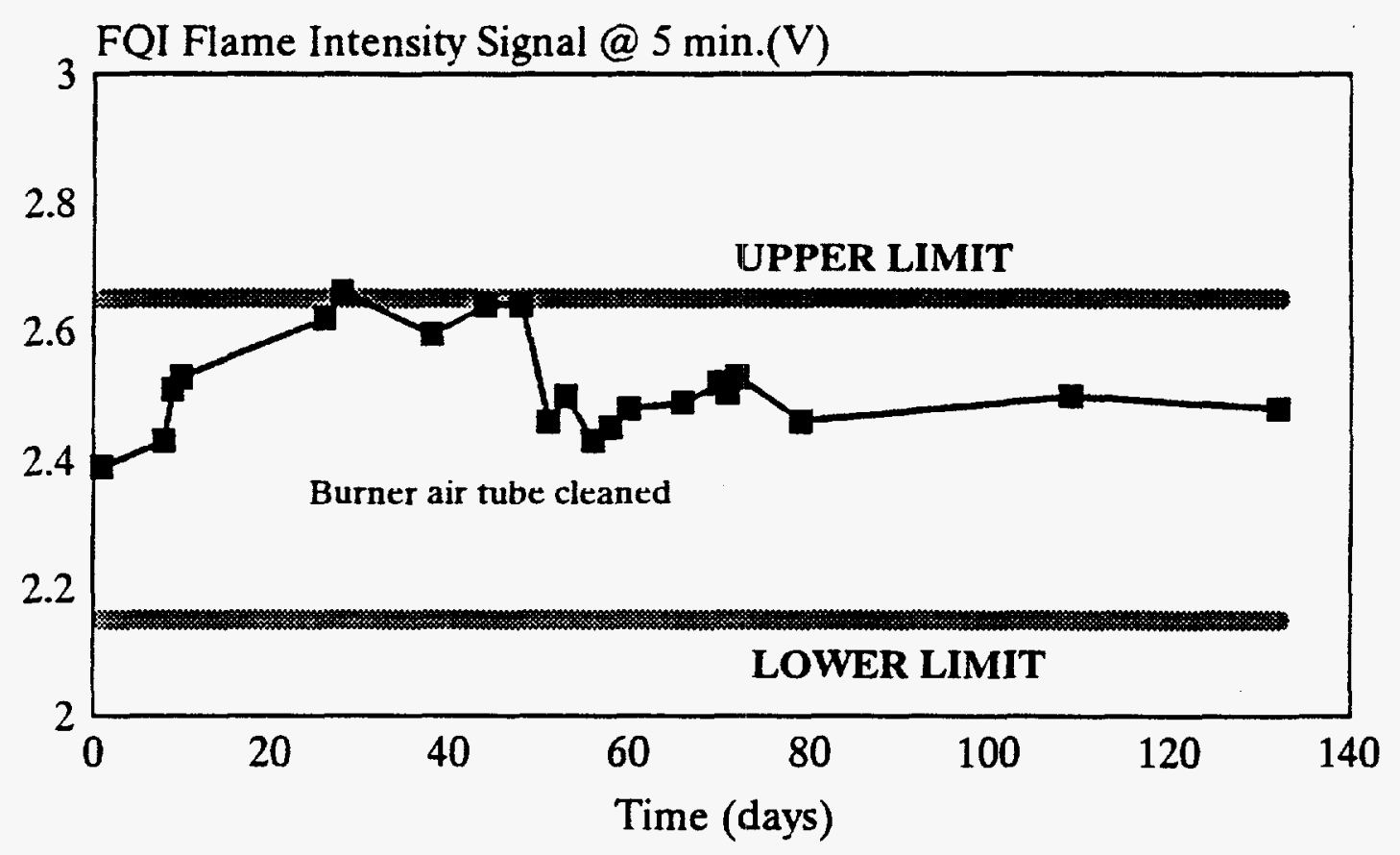

Figure 13. Trends in FQI Flame Intensity Signal. - Residential Dry Base Boiler

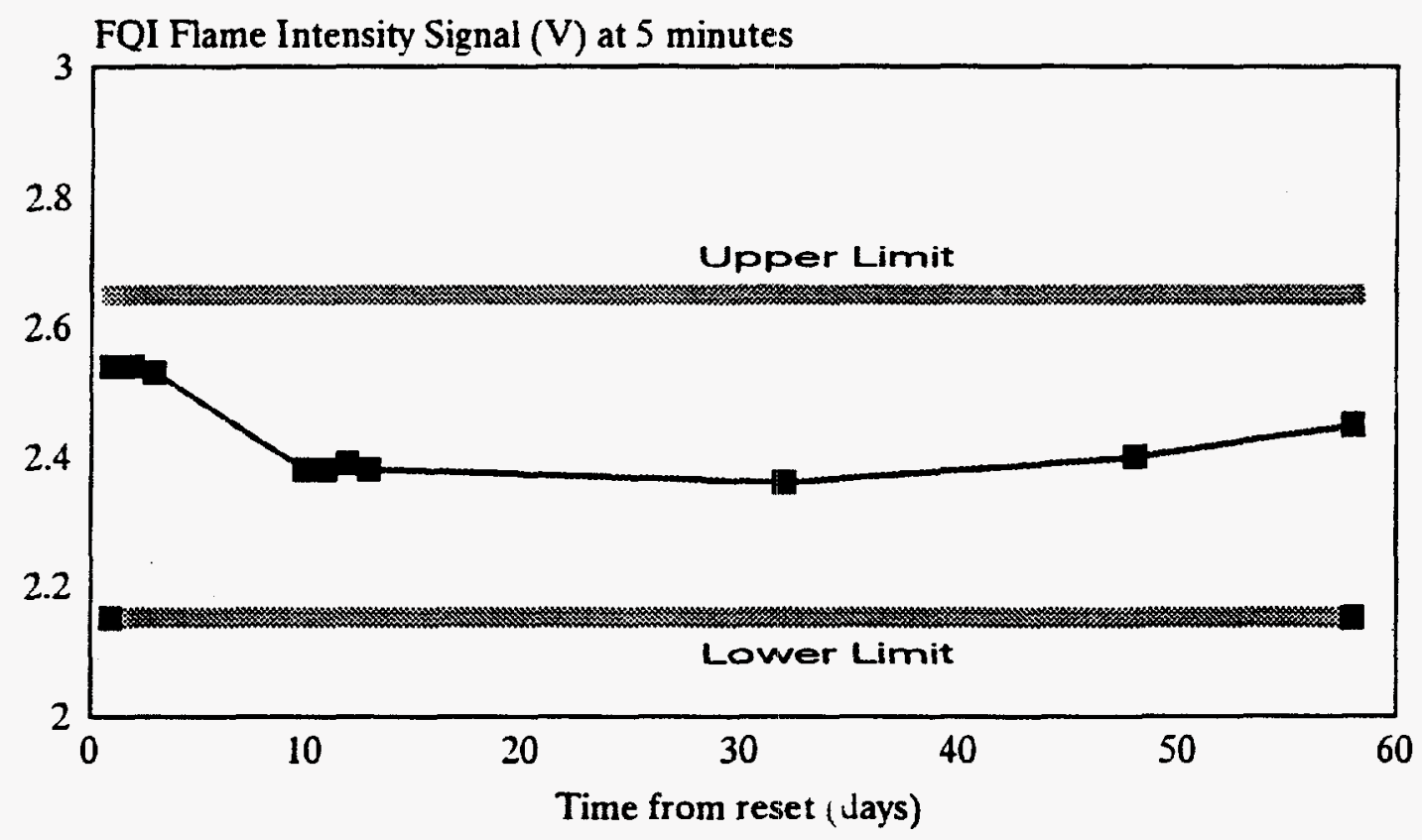

Figure 14. Trend in FQI Flame Intensity Signal. Residential Cast Iron Boiler 


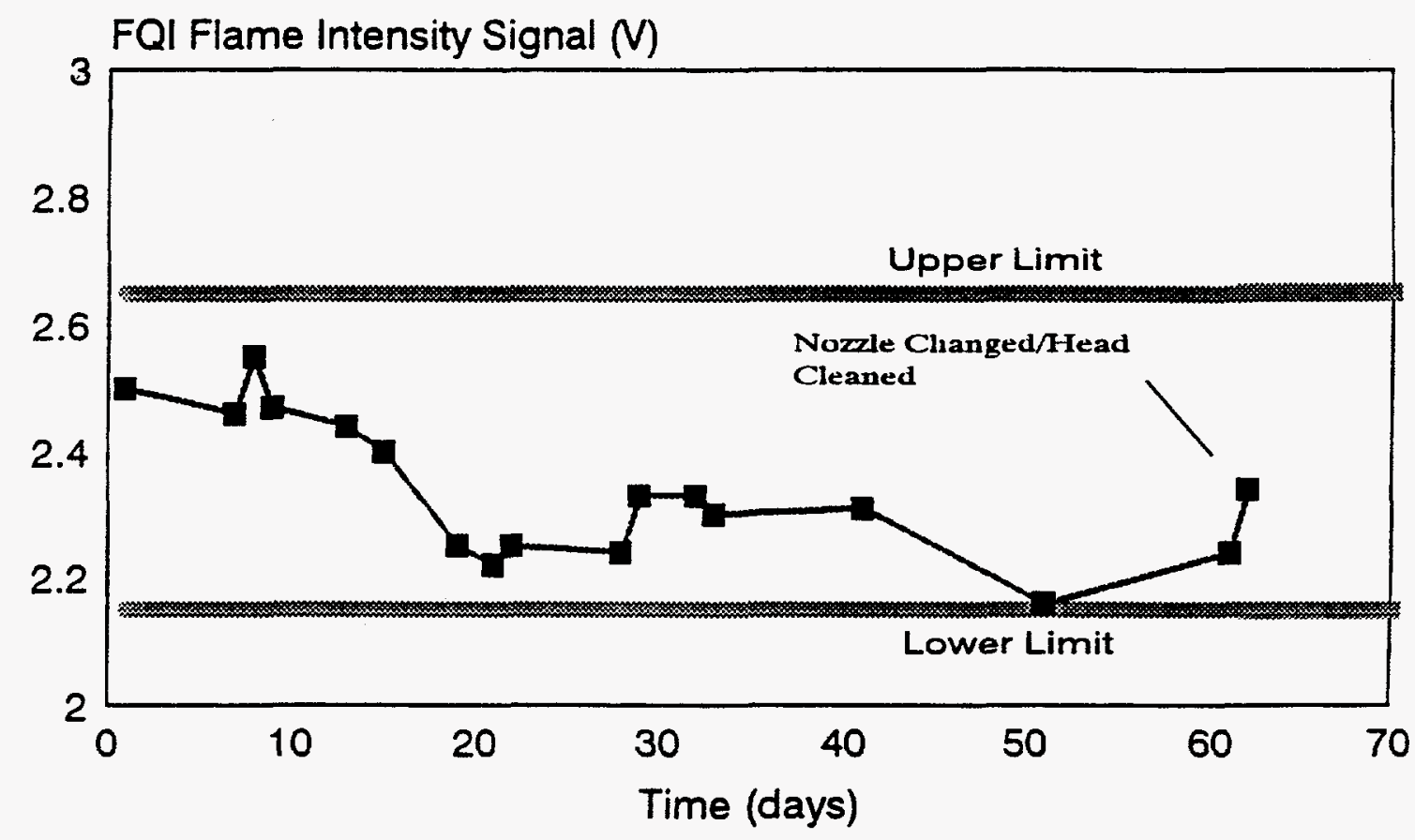

Figure 15. Trend in FQI Flame Intensity Signal - Residential, Wet Base, Steel Boiler

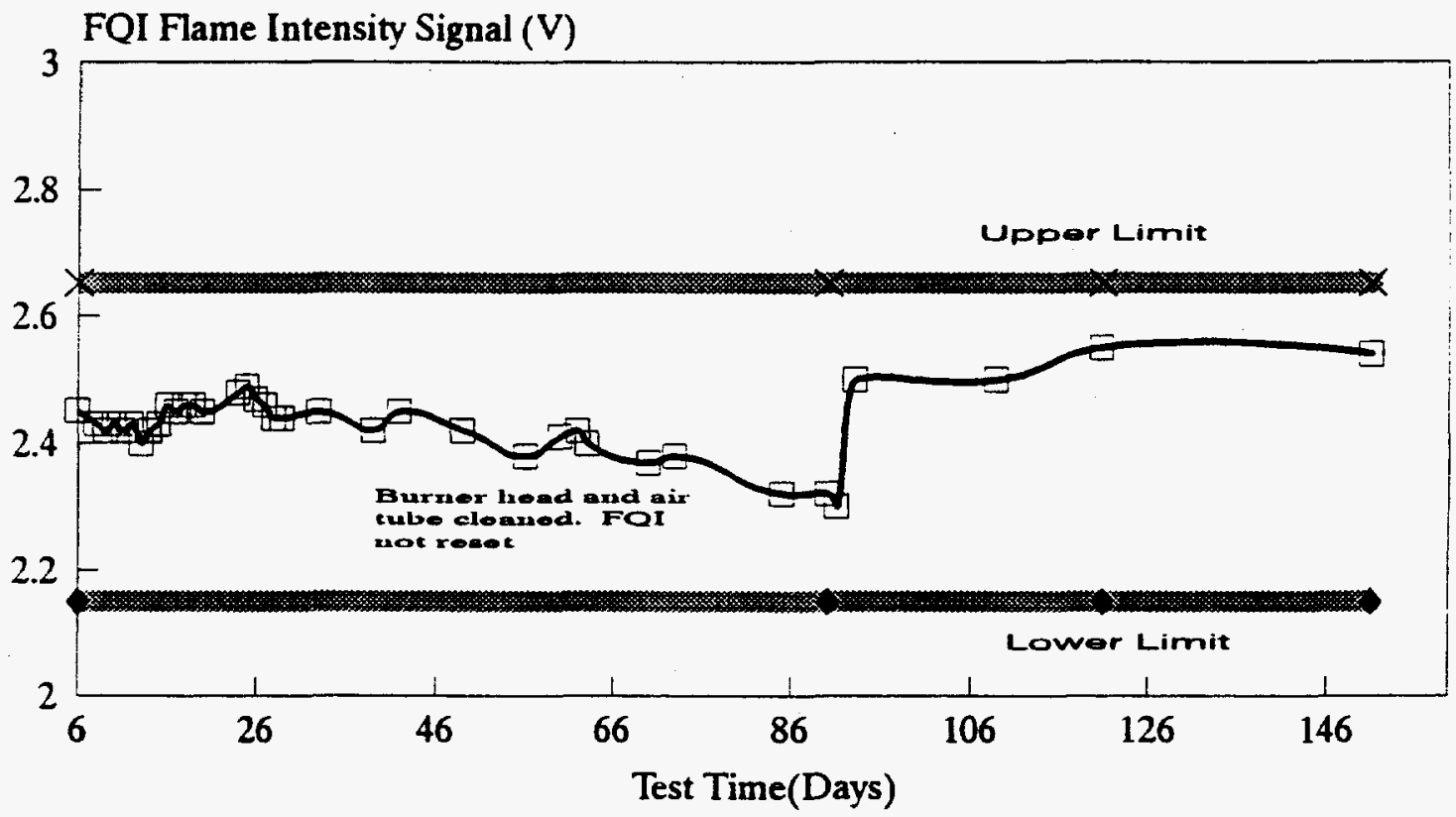

Figure 16. Trend in FQI Flame Intensity Signal - Boiler No. 6 at Long Island Nursing Home, $\mathrm{O} 2=3.6 \% ;$ Smoke $=0$ 


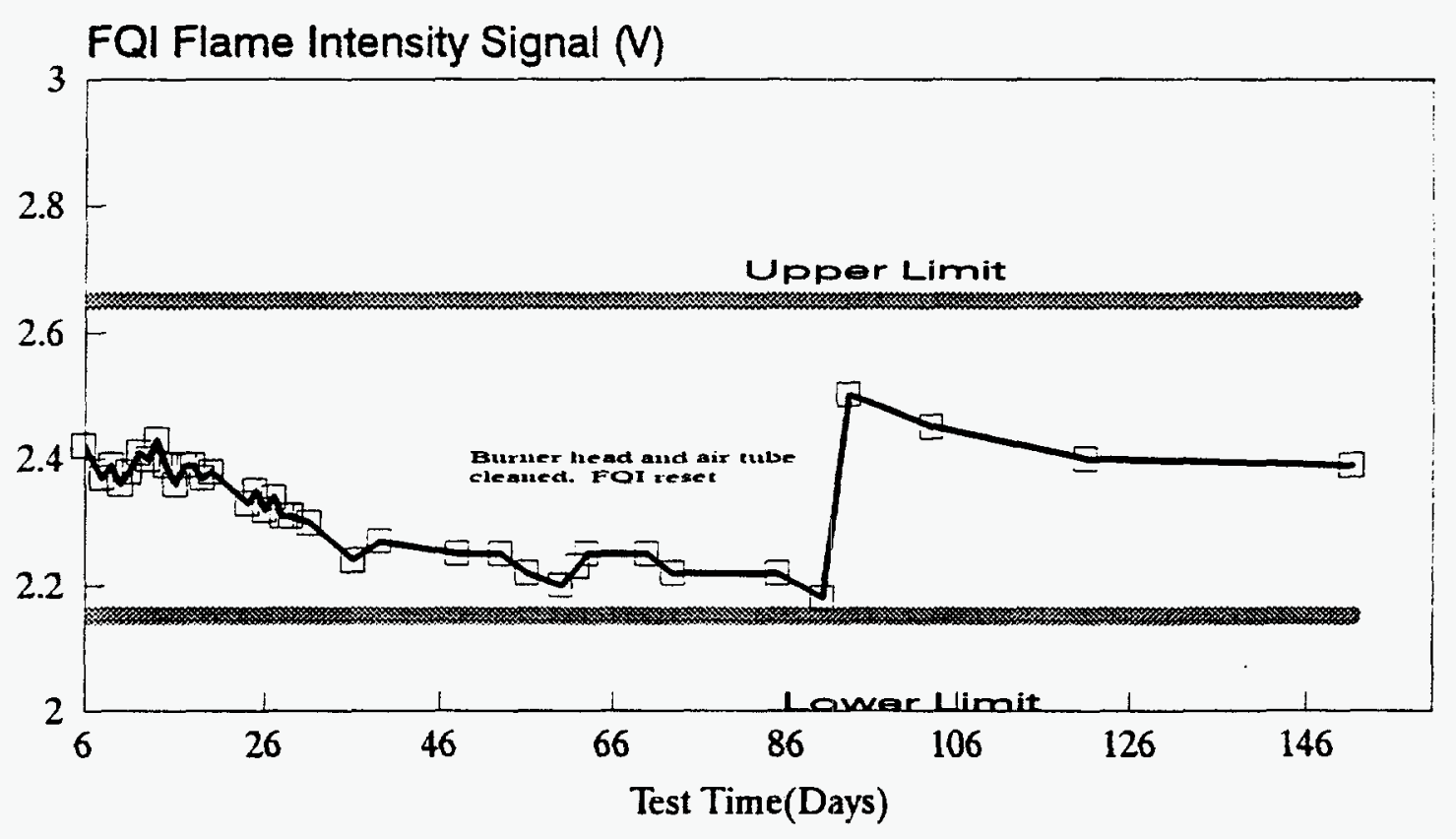

Figure 17. Trend in FQI Flame Intensity signal - Boiler No. 7 at Long Island Nursing Home $\mathrm{O} 2=7.0 \% ;$ Smoke $=0$

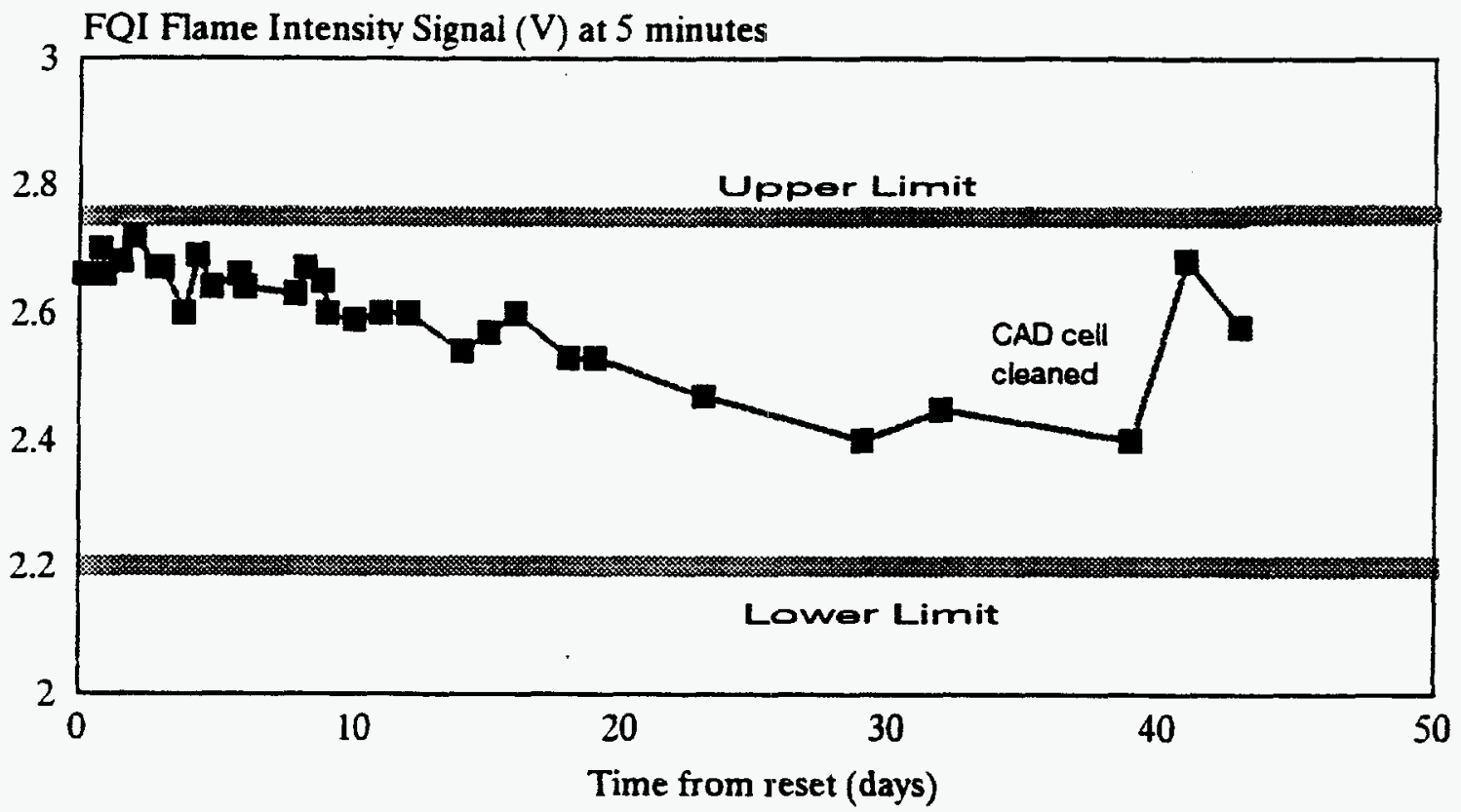

Figure 18. Trend in FQI Flame Intensity Signal - Outdoor Unit Located at the Energy Kinetics Plant in New Jersey 


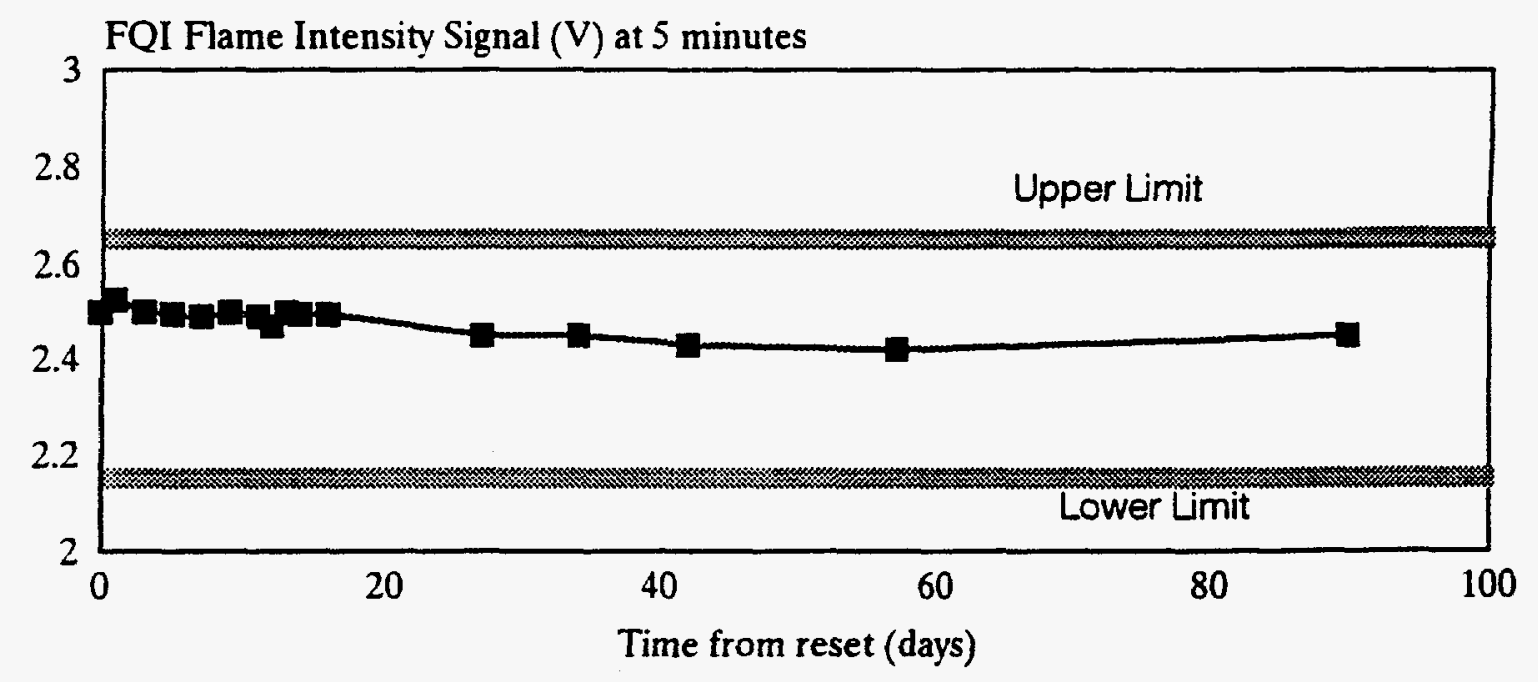

Figure 19. Trend in FQI Flame Intensity Signal. Boiler Located in Residence in New Jersey

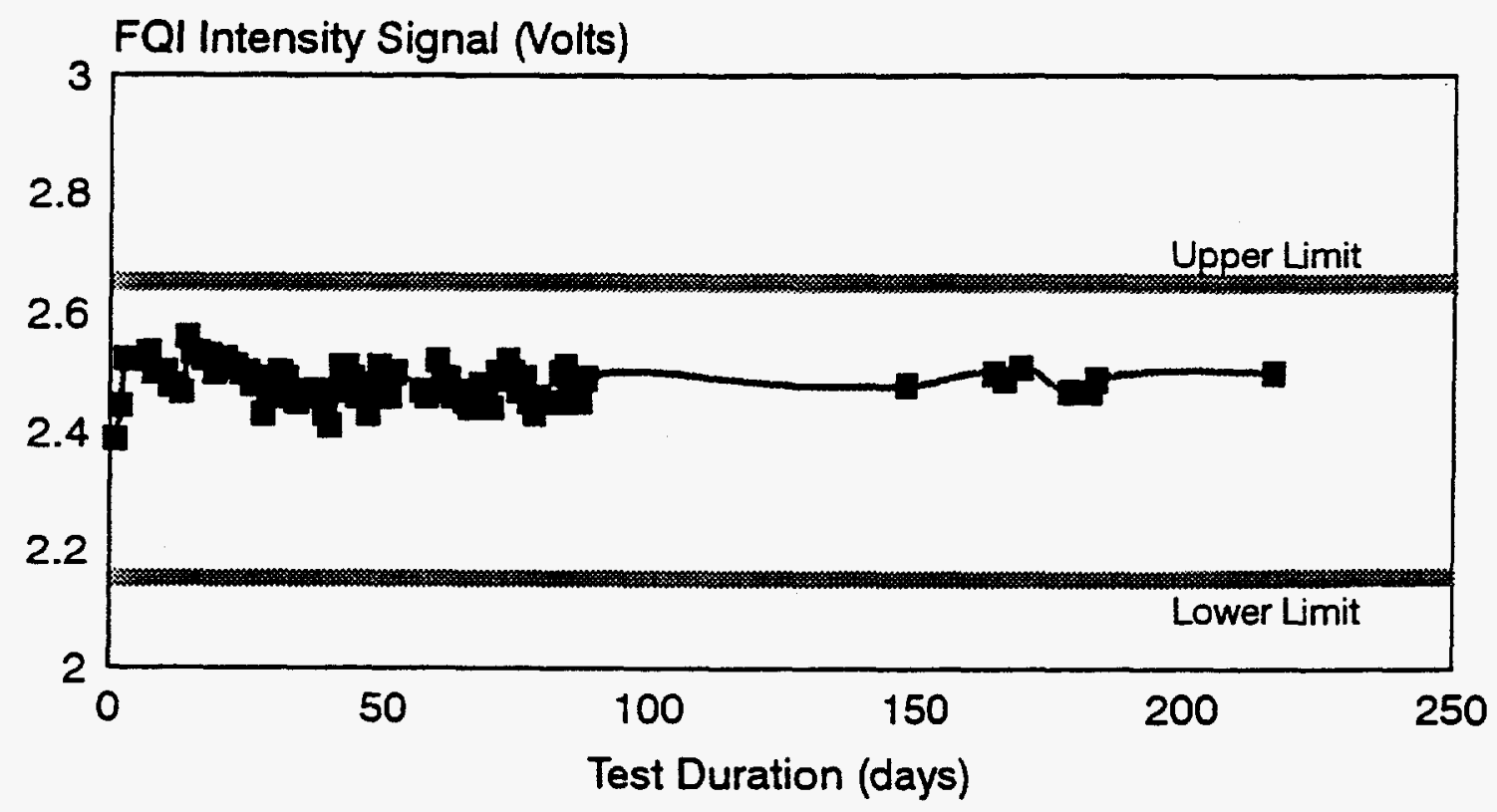

Figure 20. Trend in FQI Flame Intensity Signal. Furnace in BNL Lab Forced Cycles - 10 minutes on, 20 minutes off 
The following tests were done using the prototype developed by Energy Kinetics. Six OWL units were installed in homes located in New York near BNL. The tests sites used under this program are indicated by: Site TB, Site JW, Site YC, Site TP, Site BP and Site WL. Refer to Table 3 for a description of the heating systems at each of the test sites. All heating systems have modern flame retention head burners.

\begin{tabular}{|c|c|c|c|c|}
\hline Site & Type of Boiler & Burner Type & $\begin{array}{l}\text { Firing Rate } \\
\text { (gph) }\end{array}$ & Location \\
\hline BP & $\begin{array}{l}\text { Wet base, cast iron, w/ refractory } \\
\text { chamber }\end{array}$ & $\begin{array}{l}\text { Beckett } \\
\text { AFG }\end{array}$ & 0.75 & basement \\
\hline JW & $\begin{array}{l}\text { Wet base, cast iron, w/ refractory } \\
\text { chamber }\end{array}$ & $\begin{array}{l}\text { Beckett } \\
\text { AFG }\end{array}$ & 1.00 & ground floor \\
\hline $\mathrm{TP}$ & $\begin{array}{l}\text { Wet base, cast iron, w/ brick } \\
\text { chamber }\end{array}$ & Beckett AF & 0.85 & ground floor \\
\hline YC & Wet base, steel & Carlin EZ-1 & 0.75 & $\begin{array}{l}\text { separate } \\
\text { basement }\end{array}$ \\
\hline TB & $\begin{array}{l}\text { Dry base, steel, w/ refractory } \\
\text { chamber }\end{array}$ & Carlin EZ-1 & 0.65 & $\begin{array}{l}\text { finished } \\
\text { basement }\end{array}$ \\
\hline WL & $\begin{array}{l}\text { Dry base, steel, w/ refractory } \\
\text { chamber }\end{array}$ & Beckett AF & 0.85 & garage \\
\hline
\end{tabular}

Table 3. Description of heating systems at test sites with OWL units

The OWL units were designed to be powered by 24 volt $\mathrm{AC}$ power. In many homes the heating systems were already equipped with 24 volt $\mathrm{AC}$ sources used in thermostat-relay control circuits. In older homes which use 120 volt $A C$ thermostats a 120/24 volt AC transformer must be installed to power the OWL unit. The OWL uses its own CAD cell independent of the CAD cell used with the oil burner primary safety control. The installation of the OWL units required a special mounting bracket for the second CAD cell to be mounted in the burner housing. The heating system was then adjusted to peak efficiency with a minimum level of excess combustion air. Once the proper air/fuel adjustment was completed the installer checked the OWL's output signal with a voltmeter and adjusted the setpoint trim potentiometer with a small screwdriver.

The flame brightness sensed by the CAD cell located within the burner tube is converted to a voltage signal by the OWL. During the initial tune-up of the heating system and setup, the OWL was adjusted at the site to the setpoint voltage signal of 2.5 volts. Any drift in this signal that was observed related to changes in the operating conditions were monitored. 
Figure 21 shows typical real-time data collected from the OWL on the data logger. Several firing cycles were recorded. When the burner is off the voltage is at about 3.5 volts; a voltage drop indicates burner startup and brighter flame. This data was collected somewhat differently from prior tests in which it was noted that the voltage measured 0 volts when the burner was off. In this case the flame brightness signal stabilizes at about 2.5 volts for each cycle. The unique feature of the OWL is its sampling mechanism. An OWL unit will "determine" whether a flame is good or bad at one point during a long heating cycle. If the CAD cell "sees" the flame brightness as acceptable then the OWL indicator shows a green light; if the brightness (or voltage) is beyond preset limits then the indicator displays a red light (or amber light in some models). The homeowner was instructed to note the time and conditions when a red light occurred.

A signal or a set of signals was selected from representative heating cycles throughout the heating season. This included, for example, the first long cycle during peak demand for heat and/or hot water in the morning. The voltage signals were then plotted with respect to time to determine signal stability or trends. For these test results the voltage signals plotted were arbitrarily selected at five minutes after the burner started. In most cases, the flame was stabilized by this time. Trend data from each of the OWL units tested are shown in Figures 22 to 27 . For this flame quality indicator acceptable signals are within the range $2.1-2.9$ volts.

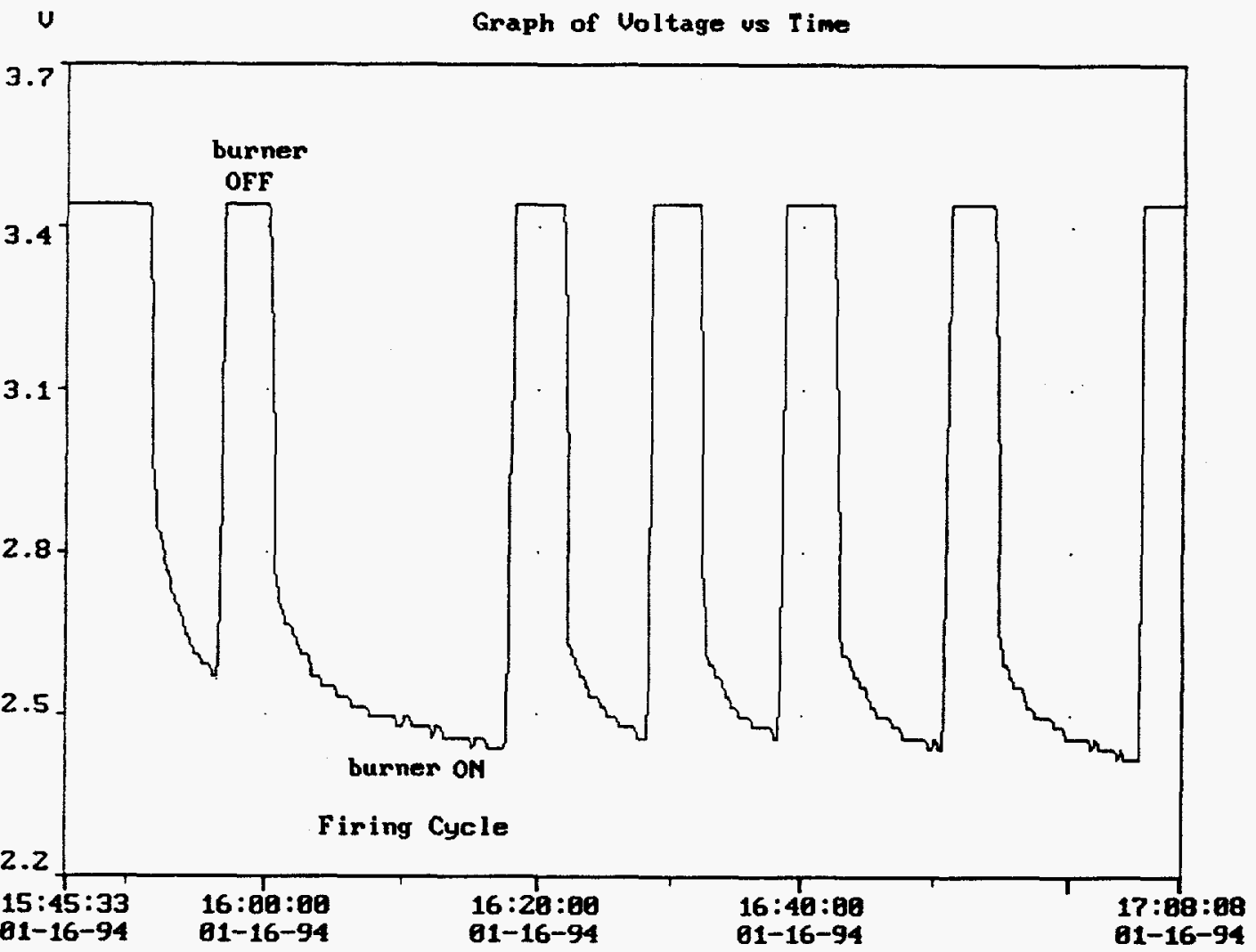

Figure 21. Typical Real-Time Data from the OWL 


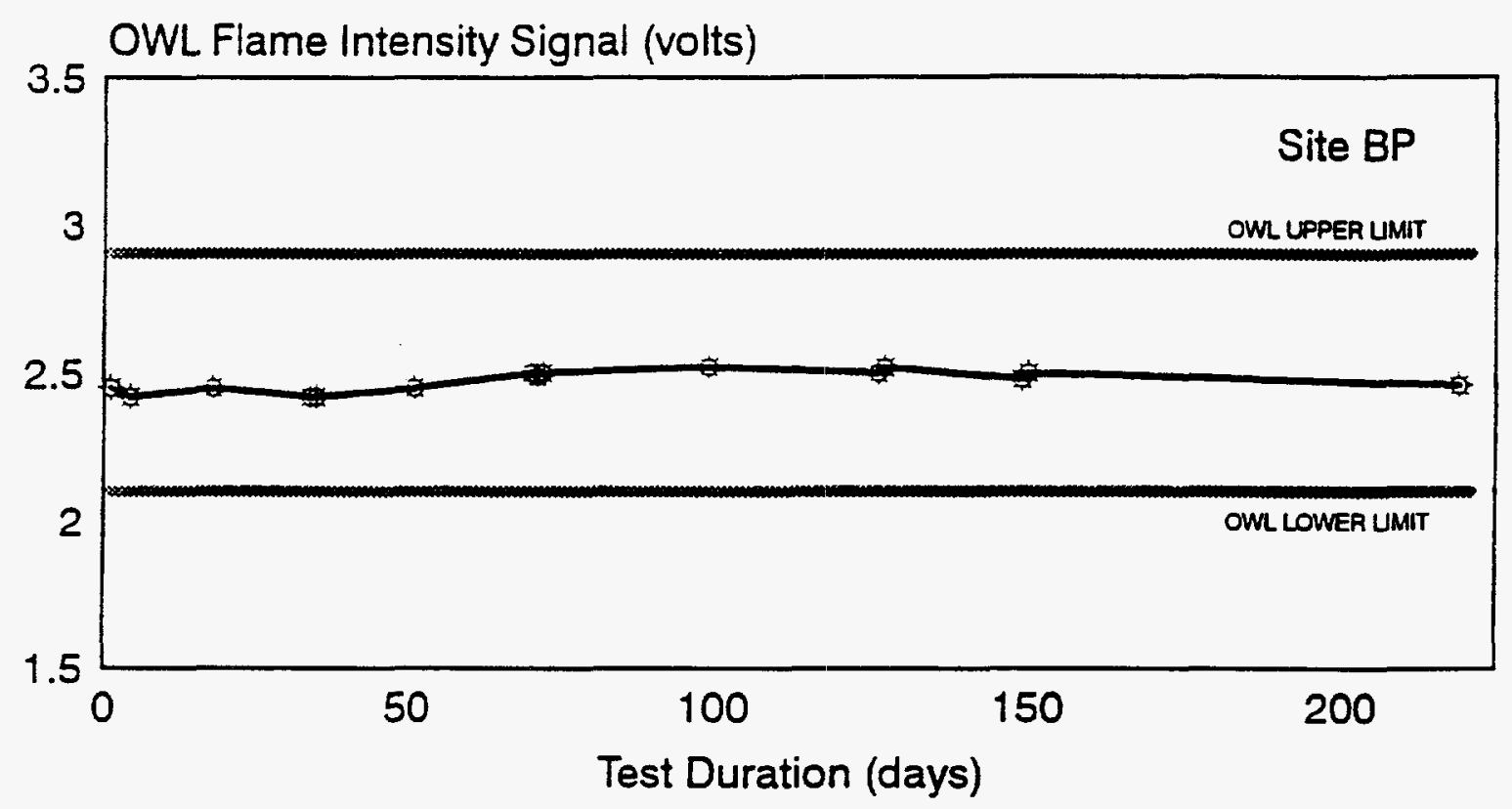

Figure 22. OWL Output Trend for Test Site BP

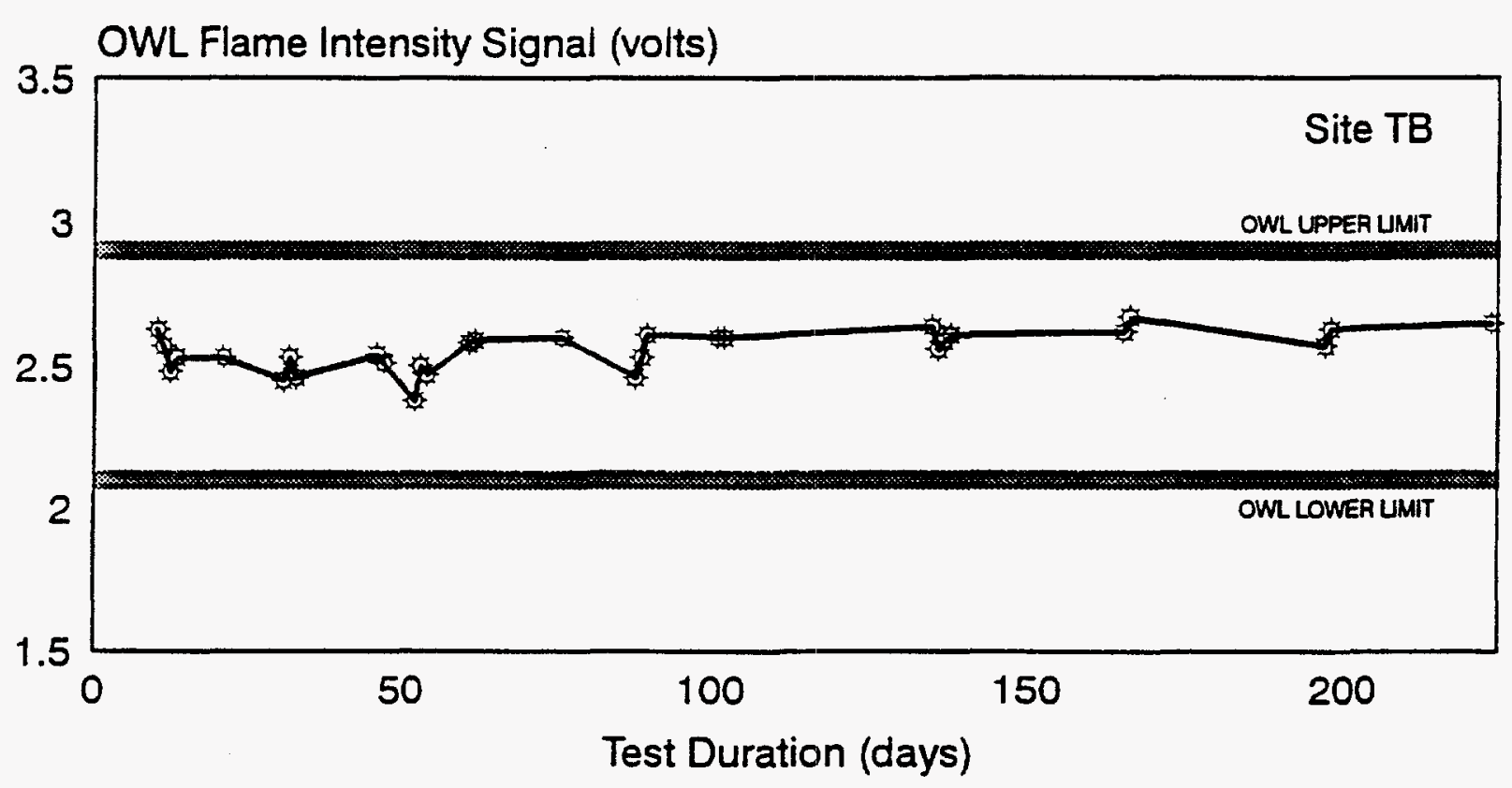

Figure 23. OWL Output Trend for Test Site TB 


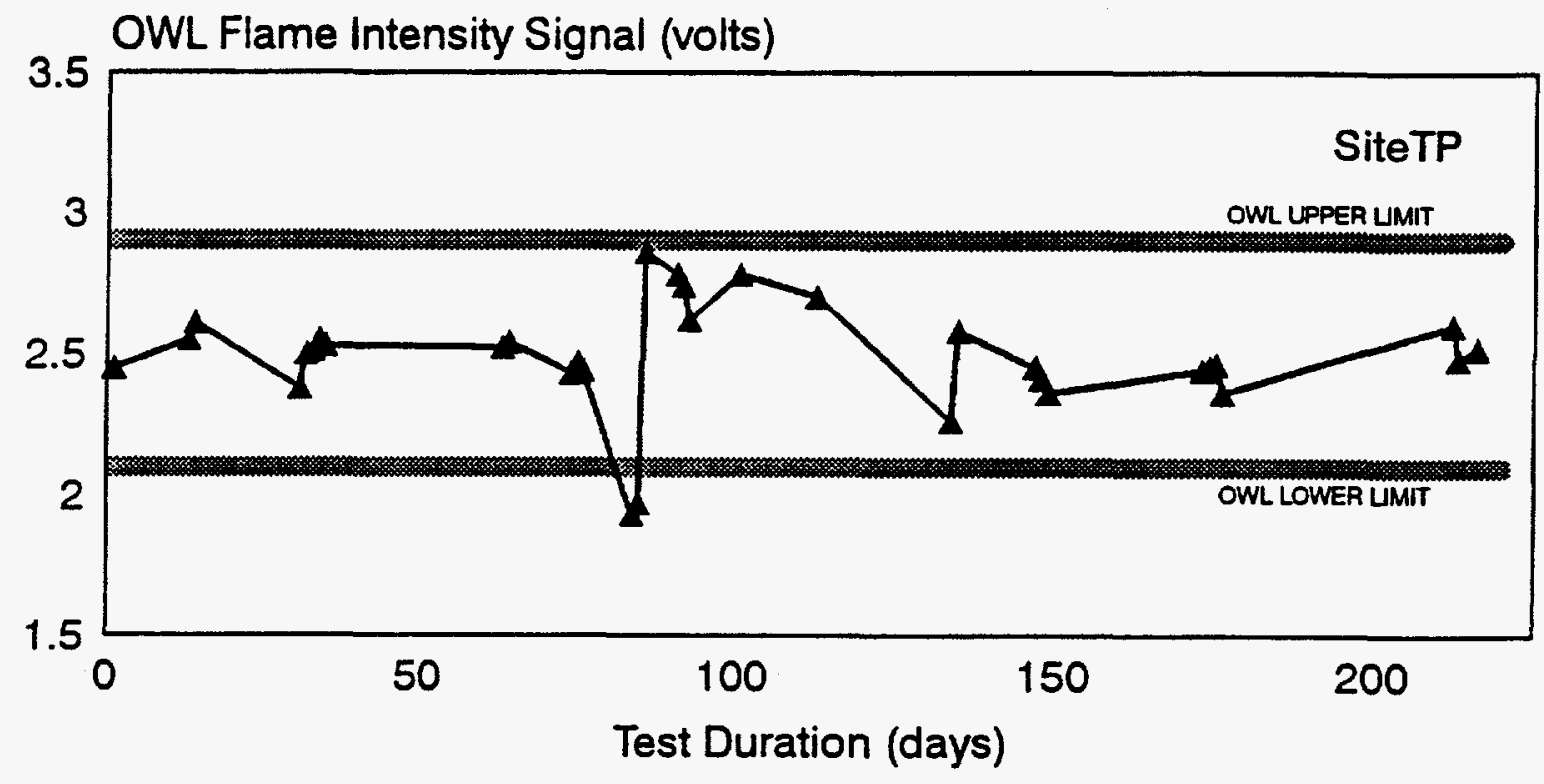

Figure 24. OWL Output Trend for Test Site TP

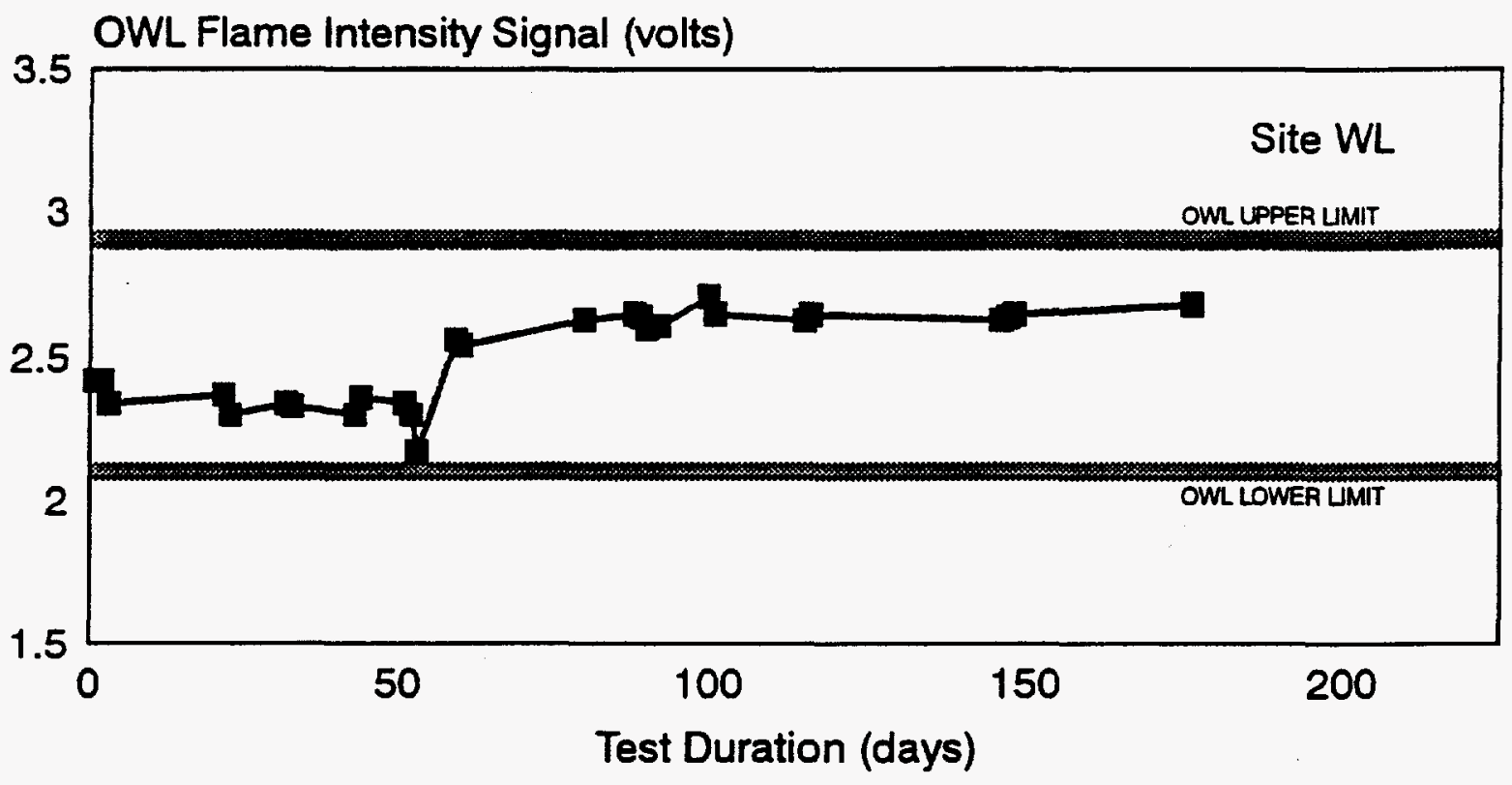

Figure 25. OWL Output Trend for Test Site WL 


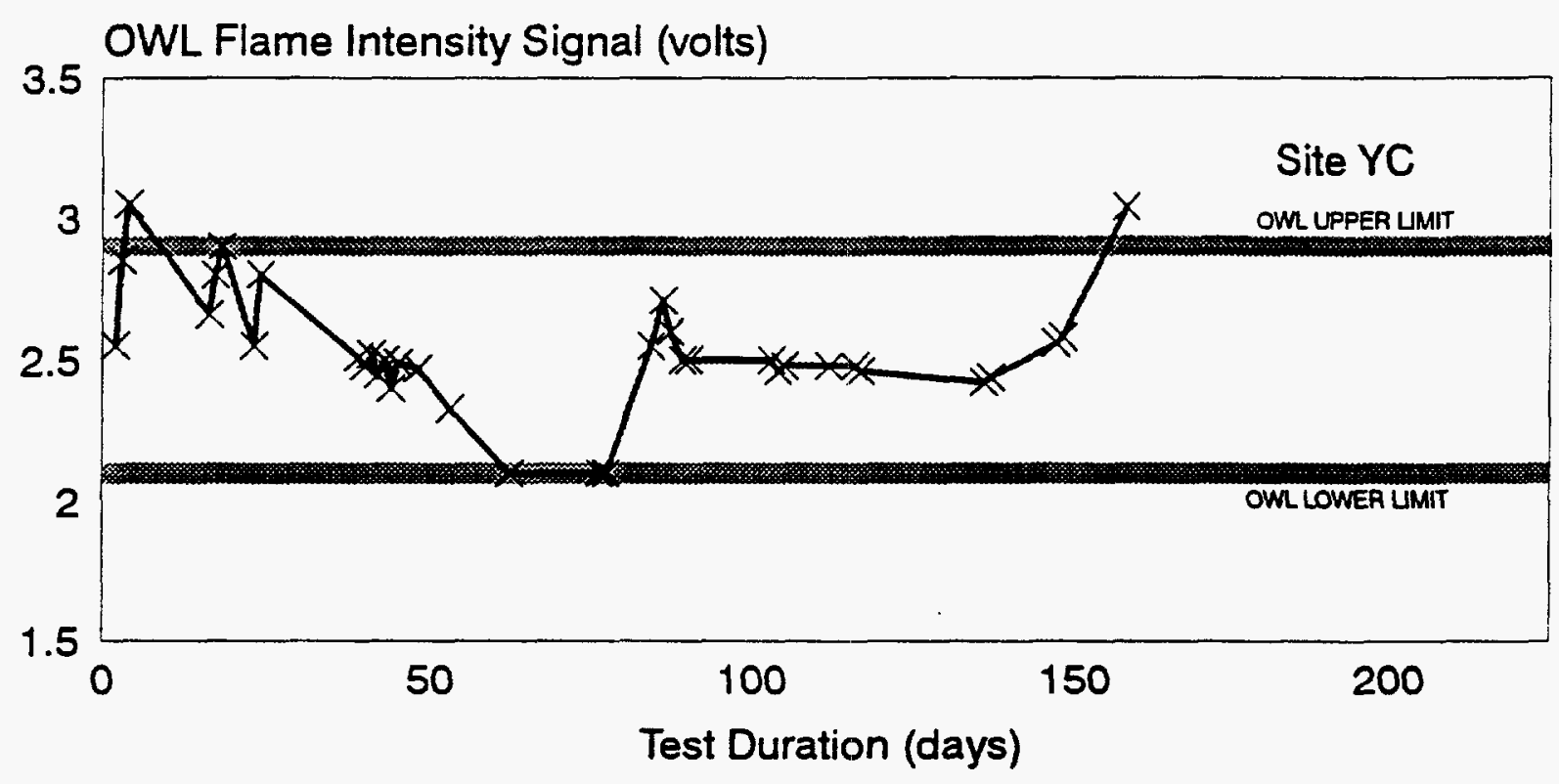

Figure 26. OWL Output Trend for Test Site YC

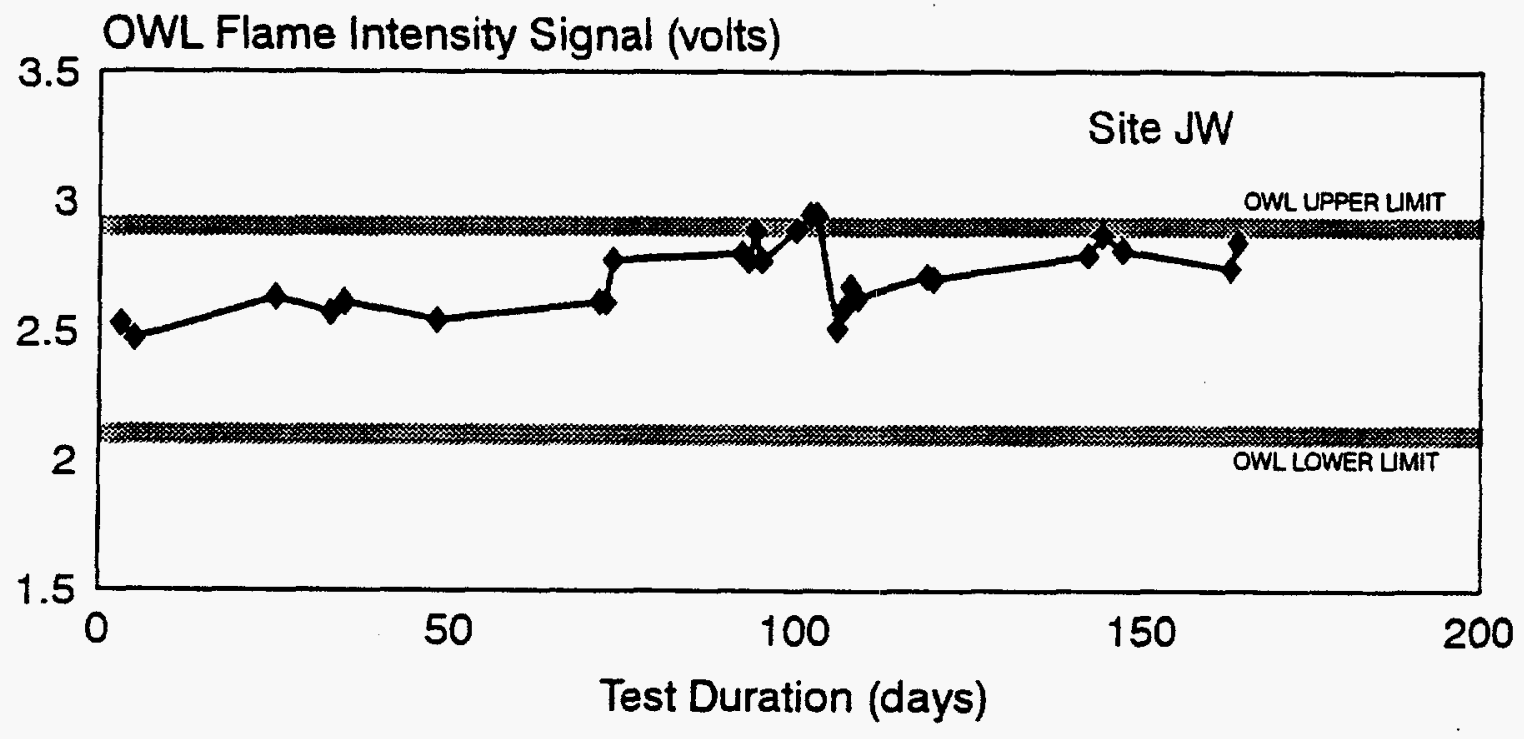

Figure 27. OWL Output Trend For Test Site JW 
A new CAD cell was installed on each burner as the sensor for the OWL. Depending on the burner design it was necessary to locate the CAD cell in different positions such that the CAD cell's view of the flame was adequate. Cad cells were placed on the fuel line in the burner tube (at Site BP); in place of the primary cad cell under the transformer (at Sites WL and JW); on a bracket below the transformer housing and near the tube wall with view of the flame through the edge of the static plate (at Site YC and TP); on a modified bracket of the burner above the fan (at Site TB).

Firing rates for all systems were 0.85 gph or lower except for one unit which was operating at $1.00 \mathrm{gph}$ at Site JW. At this higher firing rate, the burner generally stayed on for short times (3-4 minutes or less) with frequent cycling for most of the heating season. Under these circumstances the OWL would not be monitoring the condition of the flame since it samples a signal from the $\mathrm{CAD}$ cell at seven minutes after the burner starts provided the burner stays on that long. Sampling frequency and rate by the OWL depends greatly on the firing rate and the type of system in which it is installed. For an over-fired system such as the one at Site JW, the OWL would have limited effectiveness as a continuous monitoring device throughout the entire heating season.

A discussion of each site are presented along with the data. Two of the six sites, Sites BP and TB shown in Figures 22 and 23, indicated the most stable voltage signals throughout the heating season. Monitoring of the heating system operations indicated no problems requiring servicing. The remaining test sites showed either drift in the OWL output, conditions indicated by red lights on the OWL, and/or mechanical failure to the heating equipment. In December a red light condition occurred at four sites that was directly attributed to power outages.

As shown in Figure 22 the heating system at this site was very steady in its performance requiring no service and the OWL unit indicates very consistent operation right at the setpoint. The unit has been operating in a clean mode at about $5 \% \mathrm{O} 2$ with virtually little to no smoke. The burner cycles in regular patterns with the flame brightness stabilizing in 5 minutes or less. As a result the OWL voltage signals settle at the preset level with no observed drift over several months. It should be noted, however, that the CAD cell used with the OWL could not be installed under the transformer using the bracket included with the setup kit. To do so would have required that a baffle located above the blower, which is an integral part of the burner, be removed from its assembly. If the baffle were removed the amount of excess air going into the air tube changes dramatically. The CAD cell was then installed on the fuel line to make these measurements.

The data for site TB are graphed in Figure 23. This site also shows a very stable trend for the OWL output. During December a red light was observed on the OWL which was attributed to a power outage. Basic stack gas measurements made (oxygen, smoke number) showed no significant changes to the operation of the heating system. In addition, the voltage output from the OWL unit had not deviated from existing conditions. The unit was operating at about $9 \% \mathrm{O} 2$ with a smoke level of up to Smoke No. 1 during the first half of the heating season, and up to Smoke No. 2 during the latter half. 
In February (at approximately 90 days after the start of the test) a red light was observed at Site TP on the day that a fuel delivery was made to the homeowner. The fuel level in the tank was very low before the delivery and a fuel additive had been used to prevent sludge-related problems. Several days later, the primary safety switch completely shut down the power to the burner. The homeowner noticed a strong odor, smokey and rough burner startups. Upon inspection of the burner the following conditions were noted: excessive lint on the air intake of the fan, excessive oil at the bottom of the burner tube, burner was tilted back $5-7^{\circ}$, stack gas oxygen and smoke levels, however, remained the same for this system. During servicing by BNL, the lint and oil were wiped off, the $\mathrm{CAD}$ cell was adjusted for a better view of the flame, and the burner was tilted forward $1-2^{\circ}$. A red light occurred again two days later and additional changes were made to the heating system. The fuel line filter and nozzle were changed although no apparent accumulation of excessive debris was observed. A tank sample was obtained to determine the cleanliness of the oil; the oil was clean and clear. The OWL was reset again to its setpoint of 2.5 volts. Although we could not isolate the cause of the red light alert, the servicing of the system allowed it to operate acceptably without further interruption.

During the remainder of the heating season signals at site TP fluctuated significantly and on several occasions the red light was tripped. The heating system at this location consists of a cast iron, wet-base type boiler with an oversized combustion chamber. The chamber is of a clay material and upon inspection at the beginning of the heating season it was noted that the chamber was badly cracked. The tests, however, continued through the season with the system in this condition. The damage was so severe at the end of the season that the chamber collapsed upon replacement. The boiler is also poorly insulated and leaky. These factors may have contributed to the erratic cycling patterns causing wide variations in the flame brightness as the chamber heats and cools. This site will require additional instrumentation to provide real time information on the draft, and stack gas oxygen to determine possible causes of these observed signals.

A red light was observed at the end of December (approximately 50 days after the start of the test) at site WL as a result of a signal drift towards the low limit indicating that the flame brightness had increased. It was determined that with the onset of the cold weather during the heating season (after the initial setup in the fall), there were many more firing cycles and this may have contributed to the apparent increase in brightness within the combustion chamber. The OWL was reset at the beginning of January. All other operating parameters such as stack gas oxygen remain about the same as before the reset.

Although not shown in the Figure 25 the heating system at site WL had a major failure in May resulting from fouling and complete blockage of the heat exchanger sections of the boiler. Smoke levels were above the Bacharach Smoke Scale and there was no draft in the chimney or in the combustion chamber. The OWL unit, however, did not indicate a red light signal. Up until the beginning of May, the OWL had been indicating acceptable voltage signals and it is possible that the severe sooting occurred over a very short period of time, within weeks, causing the complete blockage of the boiler heat exchanger sections. A possible cause may be a partially blocked chimney resulting in very low draft. It was determined that the heating system was not running long enough during a firing cycle for the OWL to sample flame brightness. The OWL 
could not indicate the problem because it never sampled the CAD cell output signal. Heat was only needed at this time for maintaining adequate hot water for general use. The burner nozzle was examined and it appeared to have been clogged with small particles. The fuel filter did not appear to be excessively dirty or clogged. The nozzle was cleaned, and all scale and soot were removed from the boiler heat exchanger sections and weighed; the excess air setting was not changed. The boiler heat exchanger sections and the exhaust flue pipe were cleaned out and draft was reestablished. The OWL was reset according to our setup procedures and monitoring will continue through the next heating season.

Figure 26 shows that the red light on the OWL tripped on three occasions at Site YC during November-December. Several factors contributed to the problem. In this particular boiler, which is a wet-base type, and located in an unheated space, the combustion chamber does not adequately heat up and reach steady state during the firing cycles. During a series of heating cycles in which there is at least one long cycle (lasting about 10 minutes) followed by several short ones, the apparent brightness of the flame decreases while the burner is on. The OWL voltage drifts upward and can reach the upper setpoint limit where it will trigger the red light at the point when the brightness was sampled. To remedy this situation, the voltage signal was set to its setpoint (at 2.5 volts) during a long firing cycle just shortly before the signal was sampled. This was accomplished by setting the voltage 6 minutes into the firing cycle as opposed to 5 minutes as had previously been done.

Another contributing factor to the low apparent flame brightness (change towards higher voltage) at this site was associated with the possible relative increase in excess air from its preset conditions. This may have been caused by the partial blockage in the fuel supply system in which the fuel filter was found to be largely contaminated with sludge. Once the fuel filter and pump strainer were replaced and the fuel line was cleared, the OWL output signals monitored remained stable for several weeks from the middle of December until January.

During January the OWL unit triggered the red light on two occasions. There are many variables which contribute to the instability of the voltage signals from this site including widely varying firing cycle patterns and ambient room temperature. The boiler and the fuel oil tank are both located in an unheated unsealed basement and are exposed to occasional strong cold drafty ambient room conditions. In addition, a clothes dryer which is also located in this room exhausts warm air directly behind the boiler into the room. Further tests need to be made to evaluate whether and how local temperature of the room air, which also supplies the combustion air to the burner, and other parameters could affect the flame brightness.

In April the flame brightness decreased to the point where the voltage signal exceeded the upper limit. This occurred immediately after a fuel delivery although there appears to be no other adverse effects, such as burner shutdown, changes in stack oxygen levels, or drop in fuel line suction pressure. Monitoring the OWL since then without further adjustments has not shown any changes in voltage signals nor heating system operation. It is planned that tests at this site with additional instrumentation will continue through the next heating season. 
As discussed earlier, short firing cycles are common at Site JW. As a result some of the data were collected and plotted with signals at the end of 3-5 minute cycles. In Figure 27 a drift in signal towards lower flame brightness (increasing voltage) was observed during the end of January to the beginning of February. In the middle of February the OWL responded with a red light during one of the long cycles in which it successfully indicated a need for service condition. When the fuel filter and nozzle were inspected they were found to be severely contaminated with sludge that created a major restriction in the fuel supply to the nozzle. The stack gas oxygen concentration and smoke number measured did not, however, provide any indication of changes to the operation of the heating system. Due to the unusually cold temperatures during that month the fuel use was relatively high which resulted in the oil level dropping very low in the tank before the following fillup. It is believed that this may have stirred up the tank bottoms. In addition, the filter had not been changed previously for a long time. Both the filter and nozzle were replaced and the OWL was reset. It should be noted that just a "tune-up" of the heating system does not necessarily allow the OWL voltage to drift back towards its original state. In practice, the OWL must be readjusted after each service call.

During an inspection visit in June a red light was observed. For several weeks before this visit, during April, the OWL was operating within the accepted voltage range although the signals had drifted close to the high limit of 2.9 volts. Data collected on the two days prior to the site inspection indicated that there were two instances where a power loss to the OWL occurred; in one instance power was out for 40 minutes, and in the other it was out for 30 seconds. It is believed that these situations may have tripped the alarm light. During this site visit the filter and nozzle were checked for plugging; no contamination was observed. The flue gas oxygen content and the smoke number did not change since the last site visit in February when servicing and adjustments to the burner were made by BNL staff. Continued monitoring and testing is planned at this site.

In the BNL study with a limited number of field test sites, the benefits of the new prototype OWL unit was demonstrated. Specifically, it successfully identified conditions when service was required, such as blocked fuel filter and nozzle fouling, causing a red light to be indicated on the unit. Based on its specific design parameters, it has also revealed some of the limitations of its capabilities and application for some heating system configurations. The field experience revealed several unusual circumstances that caused a red light to occur, and some problems associated with the OWL setup. Brief power losses (lasting several seconds) were found to trip the red light even though there was no malfunction in the operation of the heating system. It is anticipated that changes to the circuitry will be made on newer prototypes to resolve this problem. Field experience has demonstrated that OWL setup can vary from system to system. The OWL cad cell may need to be relocated to different positions within the burner depending on the configuration of the internal parts of the burner. In some cases, the addition of the OWL cad cell interfered with either the primary control or the intake air from the blower. The initial setup of the OWL requires that the cad cell have good visibility of the flame and be secured in its position to prevent signal drift. 
For any flame quality indicator system which uses a set signal sampling time during the firing cycle, the determinations of this time period is essential to the effective operation of the unit. The firing cycle patterns depend to a great extent on the firing rate and configuration of the specific heating system. For example, at site JW the boiler cycles for very short periods normally for 2-3 minutes, occasionally 5 minutes, and rarely longer than 6 minutes. In this case, if the sampling time exceeds 6 minutes, a problem with the flame may not be noticed for an extended period of time, if at all.

It is clear that in some circumstances in which OWL signal drift was observed that further investigation of other parameters which may be affecting the unit should be investigated. It is planned that for a few of the field sites work should continue into the next heating season (199495) along with testing of new prototype units and laboratory evaluations to support the field tests as might be required.

\subsection{A Summary of Factors That Can Cause a "Red Light" Condition}

In the current FQI system, the normal set-point is 2.5 volts and the upper and lower limits are 2.15 and 2.65 volts, respectively. The field tests, as well as tests at the BNL laboratory, have identified many factors that can lead to a change in the FQI flame intensity signal and a "service required" alarm. These are summarized in Table 4. One of these has occurred several times during BNL field studies - oil in the burner air tube. At one field test site, after installation, a steady climb in the FQI signal was observed. After one month, the system was at the trip point. An inspection showed that the burner tilt was incorrect and a pool of oil had collected on the inside of the air tube. The air tube was carefully cleaned and the tilt corrected. The FQI signal returned to normal and has remained there three months later. The oil coating on the air tube surfaces increased both reflectivity and the amount of light hitting the sensor. At another site, BNL observed a severe case of oil back inside of the burner housing, probably due to a combination of poor ignition and weak draft. At this site, BNL observed a steady decrease in FQI signal. During inspection, the sensor cell was found to be dripping with oil. It was cleaned and the signal returned to near normal but the decreasing trend in the FQI signal started again suggesting the problem was back. 


\begin{tabular}{|ll|}
\hline$\bullet$ & $\begin{array}{l}\text { An increase or decrease in excess air due to changes in the air shutter position, fouling } \\
\text { of the air inlet, or blockage of the heat exchanger due to soot. }\end{array}$ \\
\hline- & Nozzle fouling. \\
\hline$-\quad$ A partial blockage of the fuel line. \\
\hline $\begin{array}{l}\text { Sooting of the sensor cad cell - this is a particular concern in cases which have massive } \\
\text { combustion chamber refractory liners and/or low off cycle draft. }\end{array}$ \\
$\begin{array}{l}\text { The buildup of soot on the burner air tube or the nozzle assembly. This can reduce the } \\
\text { amount of light which reflects back to the sensor cell. }\end{array}$ \\
$\begin{array}{l}\text { Accumulation of oil on the air tube or nozzle assembly. This glossy film can increase } \\
\text { the amount of light which reflects back to the sensor cell. }\end{array}$ \\
\hline $\begin{array}{l}\text { A very short firing cycle. In such a case the chamber may not get fully warmed up. } \\
\text { The flame at the end of the cycle is relatively cooll and emits less light than in a longer } \\
\text { cycle. Future FQI designs will eliminate this effect. }\end{array}$ \\
\hline $\begin{array}{l}\text { Damage to the sensor. If overheated the sensor cells will lose sensitivity. Current } \\
\text { placement of the sensor cell far back in the air tube has eliminated this in all cases } \\
\text { tested to date. }\end{array}$ \\
\hline $\begin{array}{l}\text { Use of an off-spec fuel which has either very high or very low aromatics content. This } \\
\text { includes lube oil. }\end{array}$ \\
\hline
\end{tabular}

Table 4. Factors Which Can Cause a "Red Light" Condition. 


\subsection{APPLICATIONS OF THE FQI ON MODULATING, OIL-FIRED HEATING SYSTEMS}

Engineering staff at the New York City's Board of Education (BOE) facility in Queens installed one of BNL's FQI samples to a horizontal, firetube boiler which fires heavy oil. The maximum firing rate is 65 gallons $/ \mathrm{hr}(9.1 \mathrm{MM} \mathrm{Btu} / \mathrm{hr})$. This is a fully modulating unit. The sensor was set up at the back of the boiler with a view directly down the combustion chamber, looking at the burner and essentially down the centerline of the flame. The FQI signal was reportedly to be very steady over the entire firing rate range. Tests were conducted by BNL staff during the heating season 1993-94 to evaluate the response to changes in excess air and draft.

Originally there was much concern about this application because the boiler has variable firing rates. As firing rate changes total flame brightness would be expected to change, making the FQI signal dependent on both firing rate and excess air level. The FQI setpoint would be correct only at one firing rate. At higher or lower firing rates flame brightness would be different and a different setpoint would be required. The staff at the BOE experimented with several alternative locations for the FQI sensor and settled on a location at the back end of the furnace, opposite from the flame. The sensor was installed inside of a pipe extended about 4" away from the brick chamber wall. No provision was made for air purging of the cad cell sensor. Staff at the $\mathrm{BOE}$ reported very good success with the $\mathrm{FQI}$ and were reportedly using it as their primary excess air sensor over a wide load range. The only other control available to them is an optical instack smoke sensor. Normally, excess air modulates with firing rate based on preset mechanical linkages.

During a BNL visit in February 1994 to the boiler house detailed measurements were made of flue gas analysis, and FQI signal over a wide range of load and excess air levels. The FQI at this site was not installed within the burner housing but rather at the back end of the combustion chamber (about 8 feet from the burner). The burner is a rotary cup type. In tests the FQI responded extremely well from the lowest to highest firing rates. Results of all of the tests are shown in Figures 28 and 29. These results are very encouraging for the possibility of using the FQI in boilers of this type.

During one occasion the test boiler went into a heavy smoke mode because of a damper failure and the FQI signalled the problem. They have asked BNL to modify the circuit to shut down the burner in the event of a red light condition. BNL has made a first version of such a modified FQI and are planning a second version which will better respond to frequent on/off cycles. 


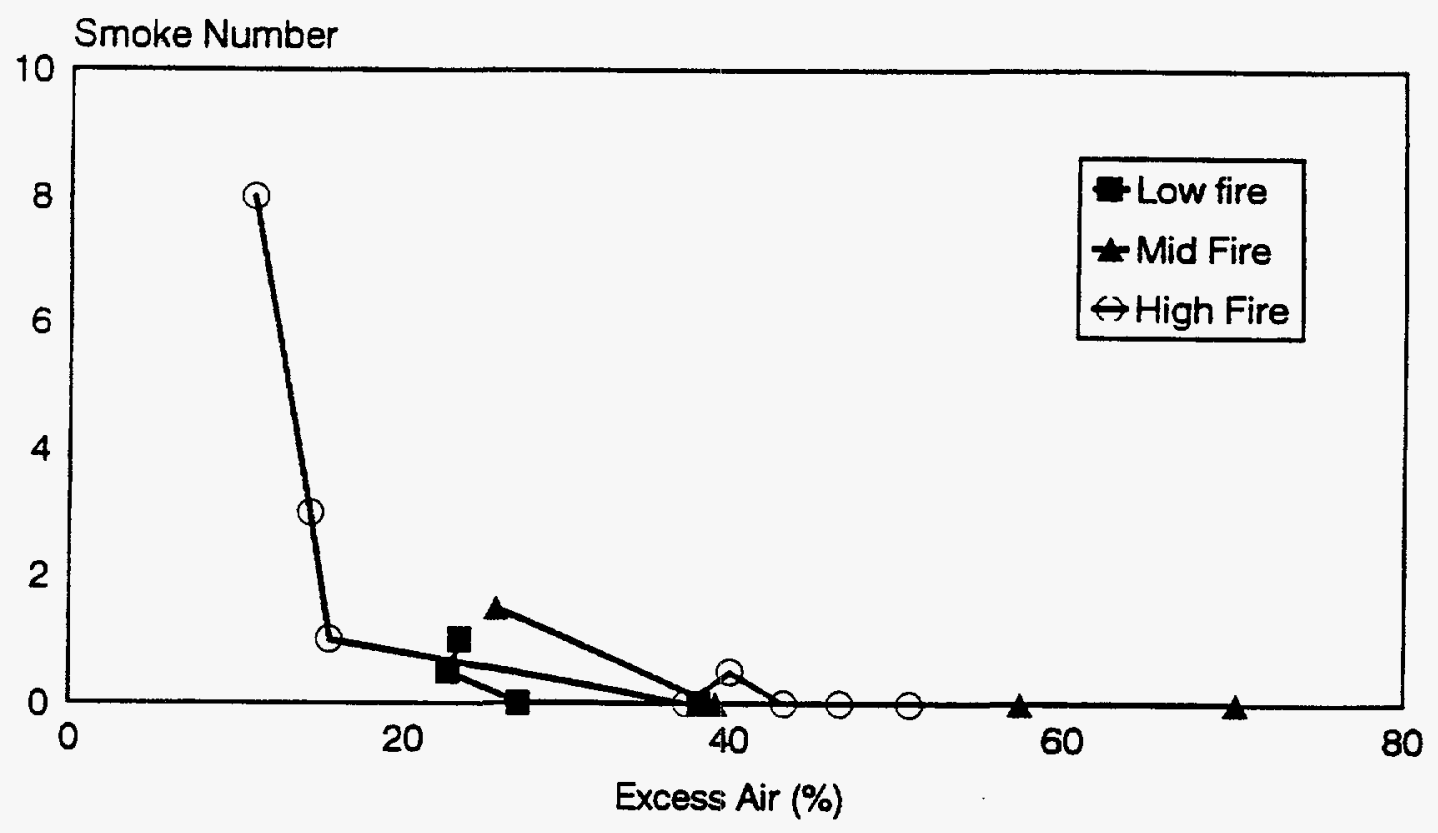

Figure 28. Results of Tests Done on Commercial Boiler at NY City Board of Education Facility. Smoke Number/Excess Air Relationship at Three Load Levels

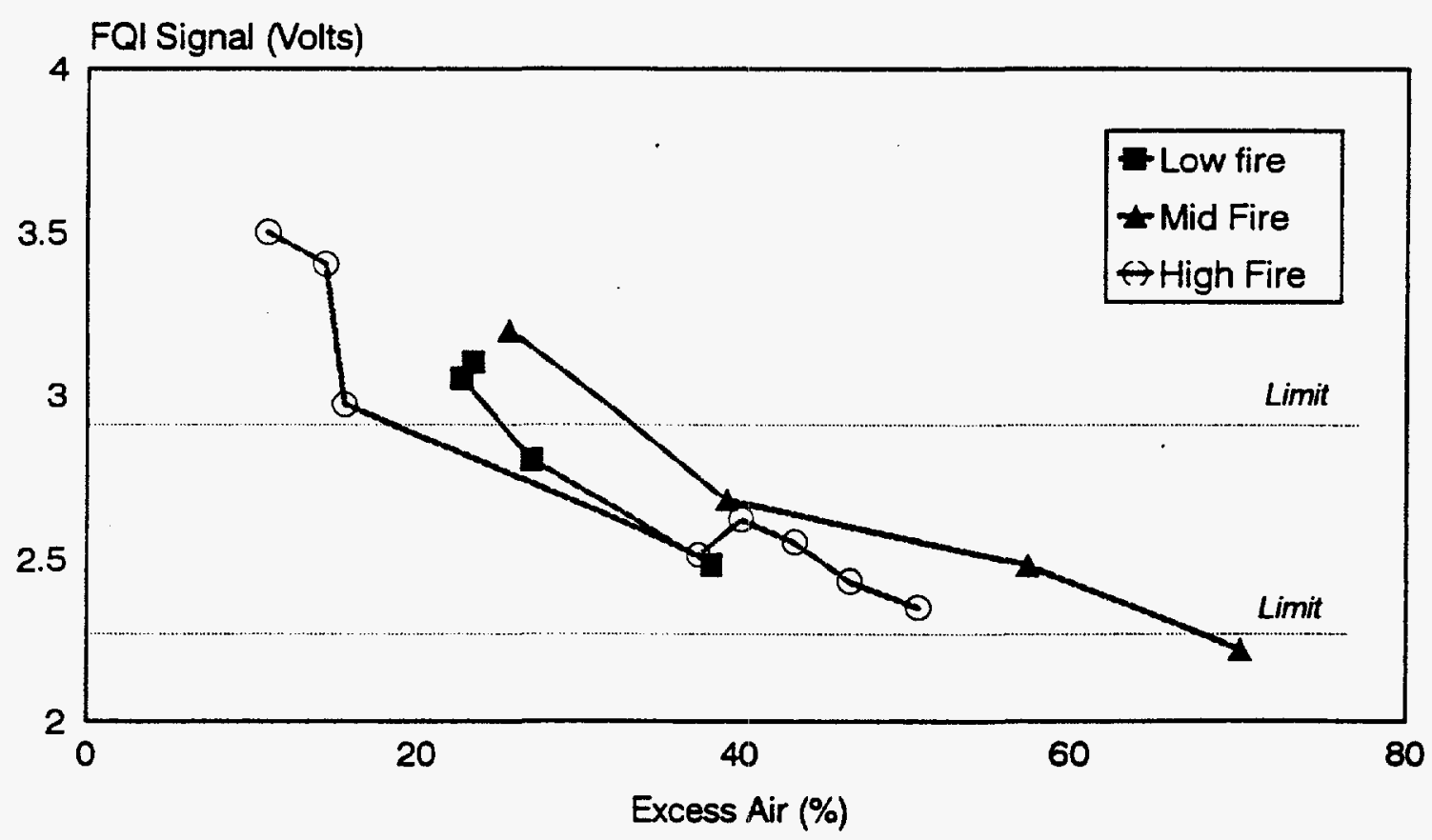

Figure 29. Results of Tests Done on Commercial Boiler at NY City Board of Education Facility. FQI Signal/Excess Air Relationship at Three Load Levels 
With the development of new prototypes and the continued interest of the oil heat industry members in the Flame Quality Indicator, future work has been planned through 1995. In particular, technical support will be provided to both Energy Kinetics and Davis Aircraft with the continuation of the field tests into the heating season 1994-95. The prototype Insight FQI developed by Davis will be included in this work. The design parameters of the Insight FQI are different from existing models of flame quality indicators. BNL's work will be used to help obtain a successful product as well as to supplement the data obtained in prior field tests.

The field evaluation of the commercial sized boiler at the New York City's Board of Education facility was very optimistic and it is planned that further in-depth field tests be done in order to promote the FQI technology in broader applications. BNL shall initiate in the fall of 1994 a closely monitored field study of a heating system located on BNL site. This unit shall have a different configuration and capacity than previously evaluated at the Board of Education facility. A $150 \mathrm{HP}$ firetube boiler with fully modulating controls shall be used. The effects of load and excess air on FQI signal, and overall reliability will be investigated. View points both ahead and behind the flame will be tested. The information developed here shall supplement the work already completed at the Board of Education facility.

During 1993 work began on a more advanced FQI concept which will provide greater capability than the current FQI. Presently the setpoint on the FQI is established on each specific unit during a normal service call. This is necessary because the brightness of the flame is dependent upon the combustion chamber that is fired into. BNL is targeting in the next FQI a system that could even be used for initial setup and which would have a setpoint independent of the specific boiler or furnace it is fired into. This would lead to better adjustment of the burners during service and improved efficiency. The approach calls for an extension of prior flame optical studies done at BNL with improved resolution, automated data acquisition and a wider spectral range, using an Optical Multichannel Analyzer (OMA). The OMA combines a spectrometer, a very large sensor array and a computer driven controller to resolve the spectrum. All wavelengths can be measured simultaneously and accurately in real time and/or stored for future analysis. This system has enabled the study of a very wide range of conditions rapidly and greatly expanding our understanding of the information in the flame spectra. During the beginning of 1994 this information was used to evaluate options for two and three color sensor systems which could be used in the next FQI version. A design study of alternative sensor/filter approaches has been completed and a system based on dual photodiode sensors with integral band pass filters has been selected for further evaluation. Circuitry for sensing and filtering the signals have been built and tested. During 1994-95 this two color system will be completed and tested in a variety of applications. For example, the advanced sensor system will be used to provide input to a control for automatic adjustment of the burner air/fuel ratio. 


\subsection{DISCUSSION AND CONCLUSIONS}

The results of all of the field tests have shown that the FQI is capable of signaling when a wide range of fault conditions have occurred and the burner should be serviced. Common faults which have been signaled include: blocked fuel line, fouled nozzle, fouled air intake, poor ignition leading to oil coating on the burner internals, and bad fuel. As the field tests have progressed and the FQI and its commercial derivatives has evolved, our understanding of the application features which affect FQI performance and sources of false alerts improves. However, because of false signals at some sites and failures to signal problems at others additional improvements are required.

One of the key factors affecting versions of the FQI which only look at the flame signal after a fixed time from burner start is the selection of that time. In many of the most recent field tests in which a 7 minute time was selected problems requiring service were not signaled. In the future the sampling time should be reduced to 5 or even 3 minutes. An example of this is site WL discussed in Section 5.6. At other sites changes in FQI signal could not be immediately related to changes in combustion performance and at these sites it is recommended that continued testing with additional data monitoring be done. A good example of this is Site YC discussed in Section 5.6. In addition to FQI signal the burner air inlet temperature, draft, flue gas temperature, circulator status, and fuel pump suction pressure will be monitored continuously in the future. It is hoped that reliability of the FQI can be improved by better understanding the interactions between these measured parameters and the FQI signal.

Industry interest in the FQI concept remains very strong. Clearly there exists the need to be able to improve the reliability of oil heat equipment. This of course carries along the benefit of improved operating efficiency of equipment in the field. 


\subsection{REFERENCES}

[1] Butcher, T. A., and Gang, W., "Advanced Control Strategies," Proceedings of the 1989 Oil Heat Technology Conference and Workshop, Brookhaven National Laboratory, Upton, NY, June 1989, Report No. BNL 52217, Paper No. 89-2.

[2] Butcher, T., Performance Control Strategies for Oil-Fired Residential Heating Systems, Brookhaven National Laboratory, July 1990, Project Report No. 52250.

[3] Sinha, R., "Field Trials of Advanced Controls for Oil-Fired Heating Equipment," Proceedings of the 1990 Oil Heat Technology Conference and Workshop, Brookhaven National Laboratory, Upton, NY, July 1992, Report No. 52340, Paper No. 91-9.

[4] Butcher, T., "Update on the BNL Flame Quality Indicator (FQI)", Proceedings of the 1991 Oil Heat Technology Conference and Workshop, Brookhaven National Laboratory, Upton, NY, July 1992, Report No. BNL 52340, Paper No. 91-8.

[5] Butcher, T.A., Gang, W, and Celebi, Y., "Applications of the Flame Quality Indicator," Proceedings of the 1993 Oil Heat Technology Conference and Workshop, Brookhaven National Laboratory, Upton, NY, September 1993, Report No. BNL 52392, Paper No. 93-4. 
APPENDICES

Appendix I: DOE Patent

Appendix II: DOE Patent Availability

Patent removed and cycled separately. PAB

46 
DEPARTMENT OF ENERGY

NOTICE OF INVENTION AVAILABLE FOR LICENSE

AGENCY: DEPARTMENT OF ENERGY, Office of General Counsel ACTION: Notice of Invention Available for License SUMMARY: The Department of Energy hereby announces that U.S. Patent No. 5,126,721, entitled "Flame Quality Monitor System For Fixed Firing Rate oil Burners" is available for license, in accordance with 35 U.S.C. 207-209. A copy of the patent may be obtained, for a modest fee, from the U.S. Patent and Trademark office, Washington, D.C. 20231.

FOR FURTHER INFORMATION: Robert J. Marchick, Office of the Assistant General Counsel for Patents, U.S. Department of Energy, 1000 Independence Avenue, S.W., Washington, D.C. 20585; Telephone $(202-586-2802)$.

SUPPLEMENTARY INFORMATION: 35 U.S.C. 207 authorizes licensing of Government-owned inventions. Implementing regulations are contained in 37 CFR 404. 37 CFR 404.7(a)(1) authorizes exclusive licensing of Government-owned inventions under certain circumstances provided that notice of the invention's availability for license has been announced in the Federal Register.

GC-42/RMARCHICK/10-24-89 "INAVLIC.FRN" 